\title{
Propuestia nutricional para un jugador de baloncesto
}

\section{Sebastián Fierro Suero}

Graduado en Ciencias de la Actividad Física y del Deporte (Universidad de Huelva)

Email: chan994@gmail.com

\section{RESUMEN:}

El objetivo de este trabajo fue aportar una propuesta real de la planificación nutricional de un joven baloncestista amateur. Para lograr este objetivo, por un lado, se ha profundizado en las características del baloncesto y la competición, para entender mejor las recomendaciones nutricionales que dan los diferentes autores para este deporte. Posteriormente, se ha profundizado en el caso concreto del sujeto de estudio. La organización de su temporada y entrenamientos, sus características antropométricas, sus hábitos alimenticios hasta ahora, etc. Con los datos obtenidos de la revisión bibliográfica y del estudio de caso, se ha llevado a cabo una planificación real de la dieta para cuatro periodos diferentes como son: pretemporada, periodo de competición, periodo de lesión y periodo de descanso. Con esto, se pretende que la nutrición sea un factor precursor del rendimiento de este deportista.

PALABRAS CLAVE: Alimentación, Dieta, Rendimiento, Deporte. 


\section{INTRODUCCIÓN}

En este artículo se va a tratar de hacer un acercamiento a las necesidades nutricionales de los jugadores de baloncesto. Concretamente el trabajo se centra en el caso de un joven baloncestista de 20 años, que juega en una liga provincial de Andalucía. Para ello, se va a estudiar las necesidades fisiológicas del deporte, sus características, las reglas que condicionan el rendimiento y esfuerzo físico, etc. De esta forma, se tratará que las recomendaciones generales nutricionales y el plan alimenticio que se haga, sea lo más acorde posible para mejorar tanto el rendimiento deportivo, como la salud de nuestro deportista, ya que éste padece además una enfermedad cardiovascular como es una hipertensión esencial. Según Terrados y Leibar (2002, citado por Rodríguez y García, 2008) son multitud los factores que pueden influir en el rendimiento deportivo, desde el propio entrenamiento, hasta el medio ambiente, pasando por otros no de menos importancia como la motivación o la nutrición. En la misma línea, Wilmore y Costill (2004, p. 452) apuntan "un rendimiento óptimo requiere un cuidadoso equilibrio dietético de los nutrientes esenciales". Eugene y Agwubuike (2012) relatan las malas prácticas nutricionales que tienen los jóvenes baloncestistas y cómo el rendimiento se ve afectado a causa de estas malas prácticas. Por ello, la nutrición y los hábitos alimenticios deben ser una preocupación importante de entrenadores y educadores que en muchas ocasiones ha sido olvidada.

\subsection{Características de la competición y el deporte}

Los partidos se juegan con reglamento FIBA (2014), por lo que su duración es de 4 periodos de 10 minutos a reloj parado, con un descanso entre el $2^{\circ}$ y el $3^{\circ}$ de 15 minutos.

La regla de 24 segundos de posición nos garantiza que los esfuerzos habitualmente van a ser cortos pero intensos. El baloncesto permite cambios ilimitados, por lo que cuando un jugador se encuentra fatigado suele ser cambiado y descansa en el banquillo. Esta característica del deporte, también hace que durante el tiempo de juego se le exija la mayor intensidad en cada jugada.

En este deporte se alternan acciones como sprints cortos y largos con descansos activos o pasivos, por lo que no podemos considerarlo como un deporte de esfuerzo continuo, sino más bien intermitente (Cometti, 2002). Otros autores como Zaragoza (1996) siguen esta misma línea, clasificando el baloncesto como un deporte aeróbico-anaeróbico alternado, donde encontramos fases cortas de acciones de máximo de esfuerzo. Lorenzo (2001) afirma que se trata de un deporte en el que los factores clave son la fuerza y la velocidad. Concretamente considera que las cualidades físicas predominantes son: velocidad de reacción, capacidad de aceleración, velocidad gestual, fuerza explosiva y resistencia a los esfuerzos máximos (velocidad, fuerza explosiva).

López Chicharro (1993, citado por González-Cross, 1994) considera el baloncesto como un deporte aeróbico-anaeróbico, es decir, que utiliza ambas vías para producir energía y Williams (1985, citado por González-Cross, 1994, p. 10) añade "La vía aeróbica para correr y la vía anaeróbica, por ejemplo, para lanzar la pelota rápidamente".

A continuación se exponen en la Tabla 1 ejemplos de diferentes gastos energéticos asociado a la práctica de baloncesto según diversos autores citados por González-Cross (1994): 
Tabla 1. Gastos energéticos asociado a la práctica de baloncesto según diversos autores adaptado de González-Cross (1994)

\begin{tabular}{cc}
\hline Autor y año & Gasto energético \\
\hline Durnin y Passomore (1967) & $7,04 \mathrm{kcal} / \mathrm{min}$. \\
OMS (1978) & $14,3 \mathrm{kcal} / \mathrm{min}$. \\
Grande Covián (1984) & $0,140 \mathrm{kcal} / \mathrm{kg} / \mathrm{min}$. \\
Gillette et al. (1985) & De 8,3 a $11,6 \mathrm{kcal} / \mathrm{min}$. \\
González Ruano (1986) & De $0,083 \mathrm{a} 0,25 \mathrm{kcal} / \mathrm{kg} / \mathrm{min}$. \\
\hline
\end{tabular}

Siguiendo a Cometti (2002) en un partido de baloncesto durante un $63 \%$ del tiempo, el jugador estar en situación de reposo (banquillo, parado o marcha). El 37\% restante "está activo", durante un $27 \%$ del tiempo realiza acciones "físicamente moderadas" a ritmo medio. Queda un $10 \%$ del tiempo (unos 16 min. $20 \mathrm{~s}$.) para las acciones rápidas e intensas.

Por otro lado, Lorenzo (2001) comenta que casi todos los estudios realizados utilizaban los mismos procedimientos para analizar los esfuerzos realizados por los jugadores de baloncesto y de los que se deducen los datos mostrados en la Tabla 2:

Tabla 2. Datos obtenidos de los estudios analizados por Lorenzo (2001)

\begin{tabular}{cccc}
\hline Parámetros & Base & Alero & Pívots \\
\hline Saltos realizados & 25 & 71 & 100 \\
Distancia & 6104 metros & 5632 metros & 5552 metros \\
Frecuencia Cardiaca & $160-195 \mathrm{ppm}$. No se encuentra menos de $110 \mathrm{pm}$ \\
Producción de lactato & \multicolumn{4}{c}{$4 \mathrm{mMol} / \mathrm{l}$} \\
Tiempo de juego & \multicolumn{3}{c}{$52 \%$ periodos juego entre $11-44 \mathrm{~s}}$. \\
& $42 \%$ periodos de pausa entre $11-40$ segundos \\
\hline
\end{tabular}

Stone y Stengerd (1993, citados por Franco, 1998) realiza una equivalencia entre las acciones técnicas de juego y los sistemas energéticos fisiológicos utilizados como se puede ver en la Tabla 3:

Tabla 3. Equivalencia entre acciones técnicas de juego y los sistemas energéticos adaptado de Stone y Stengerd (1993) y citado por Franco (1998)

\begin{tabular}{|c|c|c|}
\hline Medidas Fisiológicas & Sistema energético & Ejemplos de acciones en Baloncesto \\
\hline \multicolumn{3}{|l|}{ Potencia Anaeróbica } \\
\hline Estadio I & ATP-PC (I) & $\begin{array}{l}\text { Movimientos de velocidad, aceleraciones } \\
\text { explosivas: Rebotes, saltos, dribling, etc. }\end{array}$ \\
\hline Estadios II & AN-LA (II) & $\begin{array}{l}\text { Esfuerzos máximos anaeróbicos de } 30 \text { a } \\
60 \text { segundos: Contraataque, transiciones }\end{array}$ \\
\hline \multicolumn{3}{|l|}{ Potencia Aeróbica (AER) } \\
\hline $\begin{array}{c}\text { Estadio III (Resistencia } \\
\text { aeróbica) }\end{array}$ & AER (III) & Juego continuo: Duración partido 1,5-2h. \\
\hline Fuerza/Potencia muscular & ATP-PC (I) & Bloqueos, posición defensiva, rebotes. \\
\hline Resistencia muscular & $\begin{array}{l}\text { ATP-PC } \\
\text { AER (III) }\end{array}$ & $\begin{array}{c}\text { Juego continuo, carreras y saltos } \\
\text { repetidos }\end{array}$ \\
\hline Flexibilidad/Agilidad & ATP-PC (I) & Control corporal: Movimientos defensivos \\
\hline
\end{tabular}




\subsection{Justificación teórica de las necesidades nutricionales}

El baloncesto es un deporte intermitente en el que los jugadores pueden estar detenidos y descansando por completo durante los tiempos muertos, descansos, tiros libres, mientras son suplentes, etc. Por otro lado, como se ha visto, los jugadores pueden tanto moverse a intensidades máximas por la cancha, como puede ser el caso de correr un contraataque o una defensa $1 \times 1$, o bien desplazarse a intensidades más bajas trotando por el campo. Esta es una de las principales características de este deporte, donde la nutrición también juega un papel muy importante garantizando el aporte energético requerido por los músculos según la demanda. Arasa (2005, citado por Rodríguez y García, 2008) indica que los requerimientos energéticos son individuales, por tanto cada persona en función a parámetros como el sexo, la edad y la composición corporal tendrán unos requerimientos diferentes. De la misma forma estos requerimientos energéticos son diferentes cuando se practica una actividad física u otra. Dependen de las variables de entrenamiento, es decir, tipo de actividad realizada, frecuencia, intensidad, etcétera.

Ecónomos et al., (1993, citado por Delgado y Gil, 1998, y después citado por Rodríguez y García, 2008) recomiendan un aporte energético en torno a 50 $\mathrm{Kcal} / \mathrm{Kg} / \mathrm{día}$ o algo superior en periodo entrenamiento y pre-competición, y en torno a las $100-150 \mathrm{Kcal} / \mathrm{Kg} /$ día para los periodos competitivos. Para conseguir este aporte, lo dividen en:

- De 1 a $2 \mathrm{gr} / \mathrm{Kg} /$ día de proteínas, representa entre el $10-15 \%$ del total de Kcal

- Entre 6-13 g/Kg/día de hidratos de carbono (un 55-75\% del total de Kcal)

- Del 0-30\% de grasas, del global de Kcal.

Mishchenko y Monogarov (2001) sugieren que para un jugador de baloncesto que pese entorno a los $70 \mathrm{~kg}$, su gasto energético medio está entre 4.500-5.500 Kcal. En esa misma línea, McArdle (1990, citado por Rodríguez y García, 2008) estableció un requerimiento diario óptimo para jugadores de baloncesto de $5.610 \mathrm{Kcal}$.

Conocidas ya las necesidades de ingesta genéricas, se va tratar de hacer un acercamiento al momento de la realización de dicha ingesta. Martínez-Sanz, Urdampilleta y Mielgo-Ayuso (2013) recomiendan que entre las 36 y 48 horas antes de la sesión de entrenamiento o partido (con duración de 90 min. aprox.) debemos ingerir entre 10 y $12 \mathrm{~g} / \mathrm{kg}$ peso/día. Concretamente de 1 a 4 horas antes de realizar el ejercicio debemos ingerir de 1 a $4 \mathrm{~g} / \mathrm{kg}$ peso para aumentar la disponibilidad de hidratos de carbono (en adelante $\mathrm{HC}$ ) durante la actividad física. Del mismo modo, si hablamos de recuperación post-ejercicio debemos ingerir de 7 a $12 \mathrm{~g} / \mathrm{kg}$ peso día de HC. En esta línea, Williams (2002) recoge que, pese a haber controversia respecto a la mejora del rendimiento, algunos autores afirman que una ingesta de carbohidratos precompetitiva ayuda a mantener las reservas hepáticas y el glucógeno muscular.

Respecto a la nutrición durante la competición, según Segal et al. (1985, citado por Alarcón, Ureñá, García, y García, 2008) algunas investigaciones apuntan que es mejor reducir la ingesta de HC y aumentar la frecuencia, aproximadamente cada 15-30 minutos e ingerir de 15 a 20 gramos.

Y finalmente, en la ingesta post-competitiva según Alarcón et al. (2008) la recomendación para evitar la depleción de las reservas de glucógeno muscular es ingerir hidratos de carbono, con un suplemento proteico, entre 50 y 100 gramos, justo después de finalizar la competición. 
En referencia a la ingesta de proteínas, Martínez-Sanz et al. (2013) dicen que de forma general las proteínas no se usan como fuente energética, pero determinar la cantidad que debemos ingerir es de vital importancia en el rendimiento deportivo. Teniendo en cuenta las indicaciones de estos autores, las características del baloncesto y que el sujeto analizado es un adolescente, la ingesta proteica recomendada es de 1,5 a 2 gramos/kilogramos peso /día.

Fijándonos en la ingesta lipídica Martínez-Sanz et al. (2013) recomiendan ingerir entre un 20 y un $35 \%$ de las kilocalorías totales de lípidos, pues no sólo son un componente importante del aporte energético, sino también aportan elementos esenciales como las vitaminas $\mathrm{A}, \mathrm{D}, \mathrm{K}$ y $\mathrm{E}$. También estos autores citando a la American Dietetic Association nos hablan de la importancia de la distribución de los diferentes tipos de grasas, teniendo en cuenta que si consumimos un $35 \%$ de la ingesta kilocalórica total de grasas, tenemos que respetar que del $7-10 \%$ grasas saturadas, $10 \%$ grasas poliinsaturadas y $10-15 \%$ grasas monoinsaturadas. Cabe destacar también la importancia que dan estos autores a la ingesta de ácidos grasos omega 3 (ácidos grasos poliinsaturados) debido a sus efectos antiinflamatorios en el deporte.

Los micronutrientes, vitaminas y minerales, tienen un papel muy importante en las rutas metabólicas. Con el entrenamiento aumenta el requerimiento de micronutrientes. A continuación se expone la Tabla 4 adaptada de autores como Martínez-Sanz, et al. (2013) y la National Strength and Conditioning Association (NSCA; Earle y Baechle, 2004) sobre la ingesta diaria referencia (IDR) para personas sanas; pero además, conoceremos los niveles de ingesta tolerable (ILS).

Tabla 4. Necesidades de micronutrientes (Earle y Baechle, 2004; Martínez-Sanz et al., 2013)

\begin{tabular}{|c|c|c|c|c|c|}
\hline & \multicolumn{3}{|c|}{ Martínez-Sanz et al. (2013) } & \multicolumn{2}{|c|}{ NSCA (2004) } \\
\hline & \multicolumn{2}{|c|}{ IDR } & \multirow[t]{2}{*}{ ILS } & \multirow[t]{2}{*}{ IDR } & \multirow[t]{2}{*}{ ILS } \\
\hline & Hombre & Mujer & & & \\
\hline Vit. A ( $\mu \mathrm{g})$ & 1.000 & 800 & & 900 & 3000 \\
\hline Vit. E (mg) & 12 & 12 & & 15 & 1000 \\
\hline Vit. D ( $\mu \mathrm{g})$ & 5 & 5 & & & \\
\hline Vit. K $(\mu \mathrm{g})$ & 120 & 120 & & 120 & ND \\
\hline Vit C (mg) & 60 & 60 & & 90 & 2000 \\
\hline Tiamina (mg) & 1,2 & 0,9 & & 1,2 & ND \\
\hline Riboflavina (mg) & 1,8 & $1,3-1,4$ & & 1,3 & ND \\
\hline Niacina $(\mathrm{mg})$ & $19-20$ & $14-45$ & & 16 & 35 \\
\hline Folato $(\mu \mathrm{g})$ & 400 & 400 & & 400 & 1000 \\
\hline Vit. B6 (mg) & $1,8-2,1$ & $1,6-1,7$ & & 1,3 & 100 \\
\hline Vit. B12 ( $\mu \mathrm{g})$ & 2 & 2 & & 2,4 & ND \\
\hline $\begin{array}{l}\text { Vit. B9 } \\
\text { Biotina }(\mu \mathrm{g})\end{array}$ & 30 & 30 & & 30 & ND \\
\hline Vit. B5 (mg) & 5 & 5 & & & \\
\hline Colina (mg) & 550 & 550 & & & \\
\hline Fósforo & \multicolumn{2}{|c|}{$700-1.200$} & 4.000 & 700 & 4000 \\
\hline Hierro (mg) & $10-15$ & $15-18$ & 45 & 8 & 45 \\
\hline Magnesio (mg) & $350-400$ & 330 & 350 & $400-420$ & \\
\hline Zinc (mg) & 11 & 8 & 40 & 11 & 40 \\
\hline Cobre $(\mu \mathrm{g})$ & 900 & 900 & 10.000 & & \\
\hline
\end{tabular}




\begin{tabular}{|c|c|c|c|c|c|}
\hline Selenio $(\mu \mathrm{g})$ & $50-70$ & $50-55$ & 400 & 55 & 400 \\
\hline lodo $(\mu \mathrm{g})$ & $140-145$ & $110-115$ & 1.100 & & \\
\hline Molibdeno $(\mu \mathrm{g})$ & 45 & 45 & 2 & & \\
\hline Calcio (mg) & \multicolumn{2}{|c|}{$800-1000$} & 2.500 & 1000 & 2500 \\
\hline Flúor (mg) & \multicolumn{2}{|c|}{4} & 3 & 10 & \\
\hline Cromo $(\mu \mathrm{g})$ & \multicolumn{2}{|c|}{35} & 35 & 35 & ND \\
\hline Manganeso $(\mathrm{mg})$ & \multicolumn{2}{|c|}{2,3} & 1,8 & & \\
\hline Sodio (g) & \multicolumn{2}{|c|}{1,5} & 1,5 & & \\
\hline Potasio (g) & \multicolumn{3}{|c|}{3.500} & & \\
\hline Cloro (g) & \multicolumn{2}{|c|}{2,3} & 2,3 & & \\
\hline
\end{tabular}

Durante competiciones deportivas de alta intensidad podemos ver como el peso corporal puede oscilar antes y después, esto se debe a la pérdida hídrica a causa del sudor y la respiración (Shirreffs, 2000; citado por Ruiz, Mesa, Mula, Gutiérrez y Castillo, 2002)

Cuando una persona se deshidrata más de un $2 \%$ de su peso corporal, la frecuencia cardiaca y la temperatura del cuerpo se elevan durante el ejercicio. Si la pérdida llega a ser entre un 4-5\% del peso corporal, la capacidad para hacer esfuerzos aeróbicos prolongados disminuye entre un 20 y un 30\% (Wilmore y Costill, 2004). Ruiz et al. (2002) recomienda de forma global que la hidratación debe ser abundante tanto antes, como durante y después de la competición. Preferentemente se usará una bebida carbohidratada y con electrolitos para mantener el rendimiento. Debido a las características del baloncesto, cuya competición y entrenamiento rondan las dos horas, Ruiz et al. (2002) aconsejan una ingesta de 800-1600 ml/h. con una concentración de $6-8 \%$ de carbohidratos, y con 10-20 mmol/L de sodio.

Ruiz et al. (2002) recomiendan beber de 5 a 7 mililitros/kilogramos durante las cuatro horas antes del ejercicio. Palacios, Montalvo y Ribas (2009) recomiendan una ingesta de 400 a 600 mililitros de agua o bebida deportiva de una a dos horas antes de comenzar el ejercicio. Por su parte, Earle y Baechle (2004) aconsejan consumir al menos 0,5 litros durante las dos horas anteriores al comienzo de la actividad.

Ruiz et al. (2002) aconsejan que durante la competición, debe reponerse tanto líquido como peso hayamos perdido. El líquido aconsejado es una bebida con sodio $(110-160 \mathrm{mg} / 240 \mathrm{~mL})$ o (110-160mg/8oz). Durante la actividad se debe beber pequeñas cantidades, con intervalos regulares de tiempo, de forma que permita tanto reponer el agua, como electrolitos perdidos y mantener los niveles de glucosa en sangre (Earle y Baechle, 2004; Palacios et al., 2009)

Tras la competición, debe ingerirse $750 \mathrm{ml}$ de líquido por cada $500 \mathrm{~g}$ de pérdida de peso, igual que anteriormente preferiremos ingerir una bebida con sodio (110-270mg/240mL) o (110-270mg/8oz) o alimentos que contengan sodio para así estimular la sed y reponer la pérdida de sodio producida por el sudor (Ruiz et al. 2002). Palacios et al. (2009) proponen que la reposición de líquidos tras el ejercicio debe comenzar lo antes posible.

En cualquier caso, pese a las recomendaciones generales que nos dan los distintos autores, es importantísimo adaptar las características del sujeto, climatología del momento, respuesta fisiológica, etc. 


\section{METODOLOGÍA}

La temporada competitiva del sujeto en el que se centra el trabajo, consta de 22 partidos de liga regular, distribuidos semanalmente desde el mes de octubre hasta marzo. Por tanto, no hay un periodo específico competitivo claro, sino que la competición se distribuye a lo largo de la temporada. Además cabe destacar, que el objetivo del equipo es clasificarse para los playoff, de ser así, la temporada se alargaría hasta mediados de mayo, cuando se celebraría en un mismo fin de semana la "final four". Desde entonces hasta agosto inclusive se permanece de vacaciones, en ellas, cada jugador tiene libertad. En el caso del sujeto en estudio, al ser una persona activa y amante del deporte sigue realizando actividad física, alejándose un poco del baloncesto y centrándose en el acondicionamiento físico u otros deportes como el vóley playa, bicicleta, etc.

Tabla 5. Distribución de la temporada por meses

\begin{tabular}{lc}
\multicolumn{1}{c}{ Mes } & Periodo \\
\hline Septiembre & Pre-temporada \\
Octubre & Pre-temporada $\quad$ Temporada \\
Noviembre & Temporada \\
Diciembre & Temporada \\
Enero & Temporada \\
Febrero & Temporada \\
Marzo & Temporada \\
Abril & Posible preparación "Final 4" \\
Mayo & Final 4 \\
Junio & Vacaciones \\
Julio & Vacaciones \\
Agosto & Vacaciones \\
\hline
\end{tabular}

Se entrena 3 días por semana, de forma que lunes, miércoles y viernes hay sesión de entrenamiento y sábado la competición. El sujeto suele disponer en torno a 20- 30 minutos de juego por partido. Los desplazamientos para los partidos son cortos y no duran más de 1 hora en su mayoría. Por tanto, el equipo no se concentra, ni viaja días antes de los encuentros. Por ello, las comidas se realizan en casa individualmente sin ningún control por parte del equipo técnico del club.

Tabla 6. Distribución de los días de entrenamiento

\begin{tabular}{|c|c|c|c|c|c|c|}
\hline Lunes & Martes & Miércoles & Jueves & Viernes & Sábado & Domingo \\
\hline Entreno & Descanso & Entreno & Descanso & Entreno & Partido & Descanso \\
\hline
\end{tabular}




\subsection{Característica del sujeto}

En este apartado, se recogen los datos antropométricos del jugador de baloncesto para, a raíz de los datos obtenidos, tratar de hacer las recomendaciones dietéticas personalizadas lo más acorde posible. A continuación se exponen los datos obtenidos en los diferentes test:

- Fecha de las mediciones: 11 Abril 2015

- Edad: 20 años

- Sexo: Hombre

- Peso actual : $65 \mathrm{~kg}$

- Altura: $180 \mathrm{~cm}$.

- Cálculo del peso ldeal $(\mathrm{kg})$
- Brocca: 81
- Lorenz: 72,5
- MLIC: 72,5

- Gasto calórico:

- Harris y Benedict: 1.724, $65 \mathrm{Kcal}$

- Gasto calórico de la OMS/FAO: 1.766,6 Kcal

- Gasto calórico realizado durante el ejercicio de la OMS/FAO : 3.102,31 Kcal

- Complexión:

Nos permite conocer la morfología del sujeto complementando la información que aporta la talla y el peso. La complexión de un sujeto se conoce a través de la relación entre la talla y el perímetro de la muñeca.

- Circunferencia de la muñeca $=16.5 \mathrm{~cm}$.

- Complexión = 10,9 cm. (pequeña)

- Relación cintura cadera:

- Circunferencia de la cintura: $81 \mathrm{~cm}$

- Circunferencia de la cadera: $97 \mathrm{~cm}$

Los valores normales son:

$$
\begin{array}{ll}
\checkmark & \text { Hombres }>0,8 \\
\checkmark & \text { Mujeres }>0,95
\end{array}
$$

- El dato obtenido es 0,83 por lo que se considera normal (ver Figura 1) 


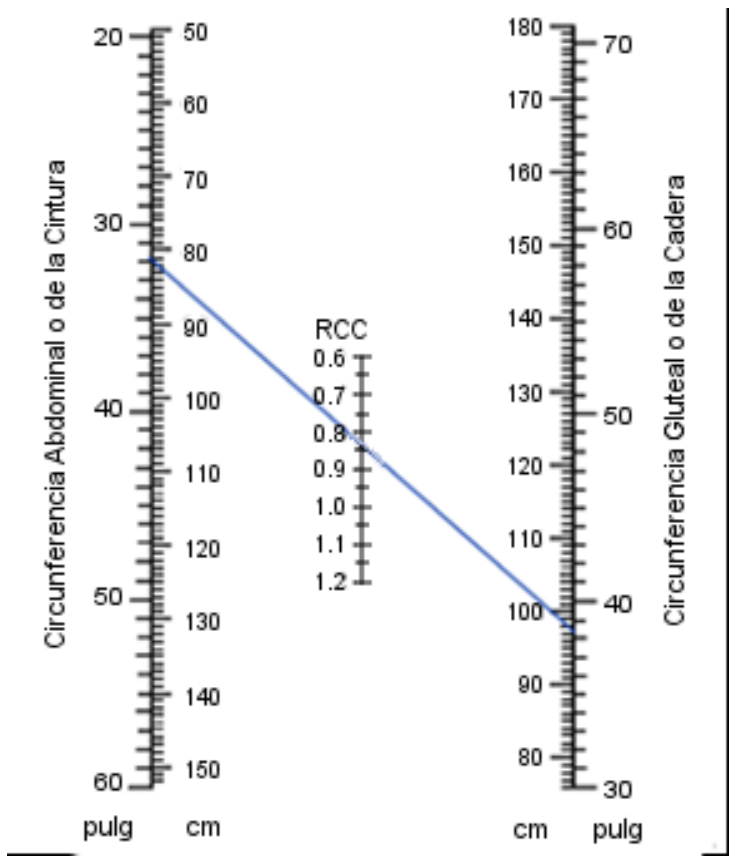

Figura 1. Nomograma para la determinación de la razón cintura/cadera

- $\underline{I M C}$

- Índice de Quetelet: 20,06 (Al límite inferior del valor normal)

- IMC Ponderal: El valor medio es 43 y el rango de normalidad se mueve entre 38-45. El resultado obtenido es de 44,76 (normal)

- Densidad corporal

- Ecuación de Jackson y Pollock $1.3279 \mathrm{~g} / \mathrm{cm}^{3}$.

- Ecuación de Pollock, Willmore y Fox $1.0838 \mathrm{~g} / \mathrm{cm}^{3}$.

- Somatocarta: Nos habla sobre la forma corporal (Figura 2).

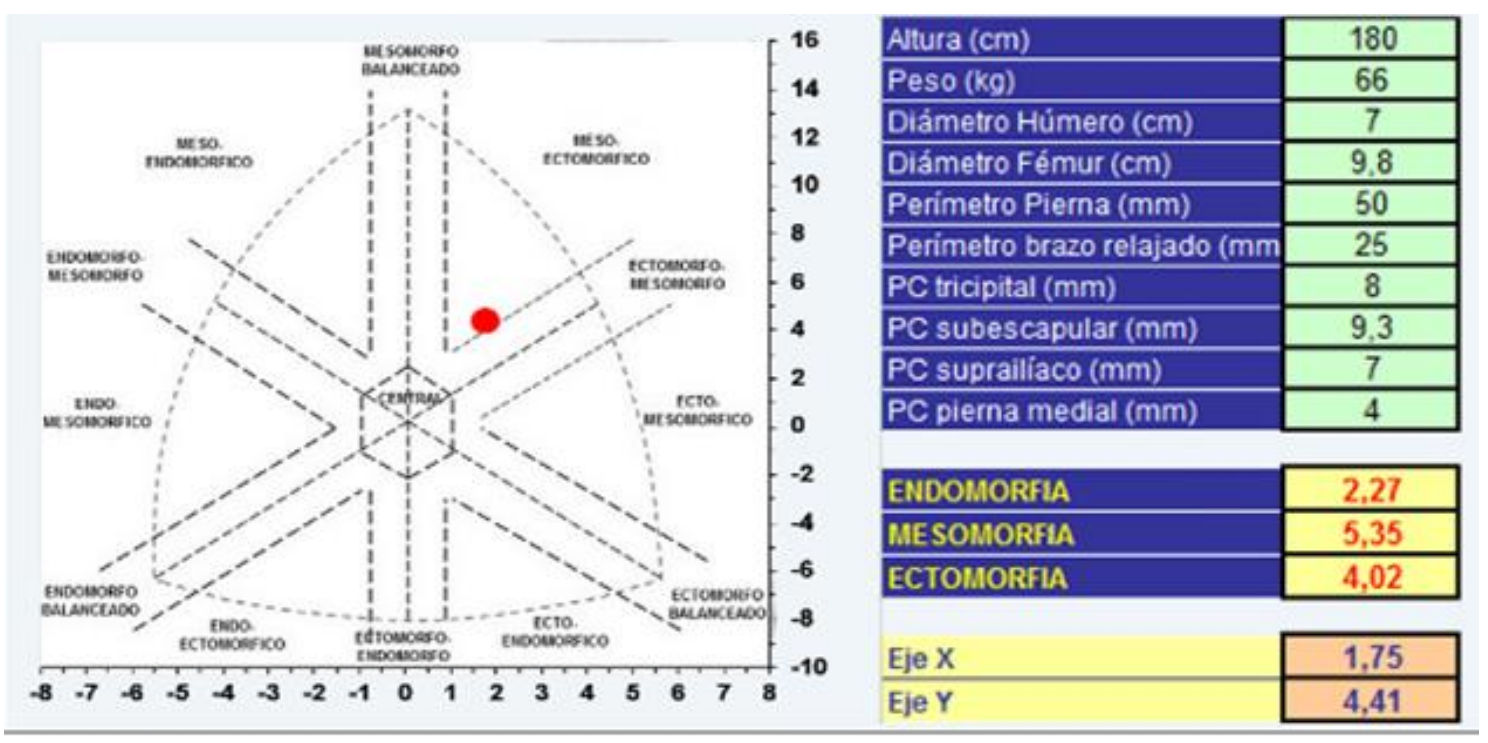

Figura 2. Resultados de la somatocarta del sujeto 
Los resultados nos reflejan una ectomesomorfia. Es decir, la mesomorfia es dominante y la ectomorfia es mayor que la endomorfia. En la Figura 3 se puede ver la comparación de los resultados del sujeto analizado con un baloncestista profesional siguiendo a Cabañas-Armesilla y Maestre-López (2009, citado por Martínez-Sanz, Otegui, Guerrero y Barrios, 2011) cuyos resultados serán 0,6 para el eje X y 4,6 para el eje $\mathrm{Y}$, por lo que son bastante cercanos.

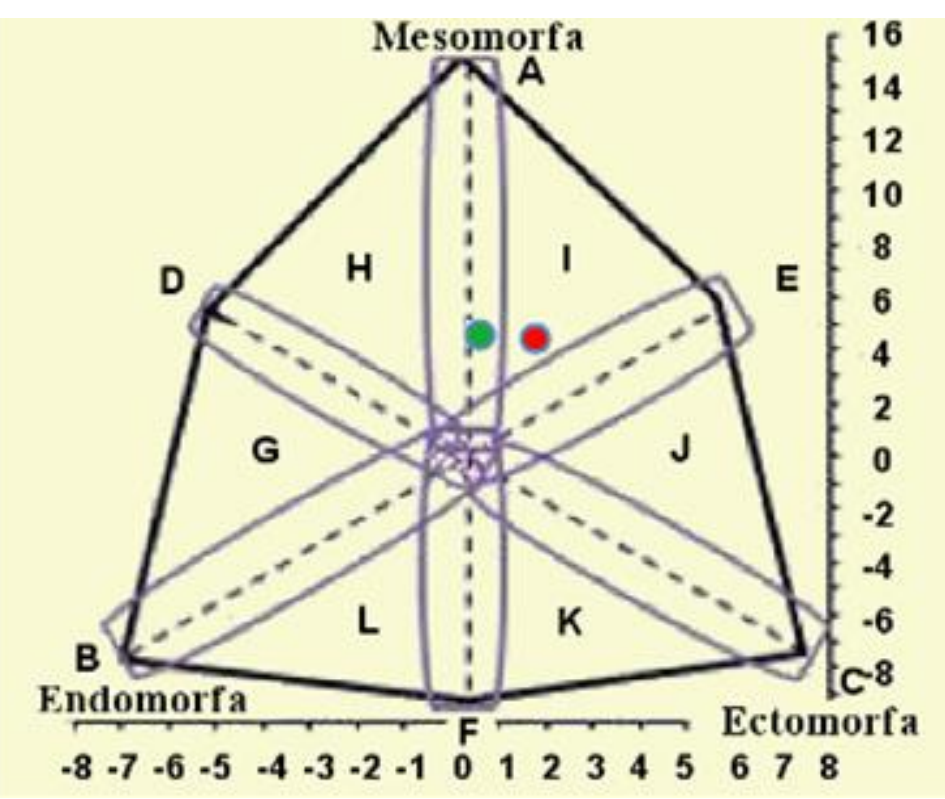

Figura 3. Comparación con los resultados de la somatocarta de baloncestistas de CabañasArmesilla y Maestre-López (2009, citado por Martínez-Sanz et al., 2011).

- Bioimpedancia

Los resultados de la bioimpedancia (Inbody 230) vienen a certificar los datos ya obtenidos de la somatocarta. En la Tabla 9 se hace un resumen de los datos más relevantes como peso, masa grasa, masa muscular, porcentajes etc.

Tabla 9. Resultados de la Bioimpedancia (Inbdoy 230)

\begin{tabular}{ccccc}
\hline Variable & $\mathrm{Kg}$ & $\%$ & Ideal $(\mathrm{kg})$ & Diferencia $(\mathrm{kg})$ \\
\hline Peso & 66,4 & $93,2 \%$ respecto al peso ideal & 71,3 & $-4,9$ \\
Masa grasa & 8 & $12 \%$ del peso total & 10 a 20 & 0 \\
Masa libre de grasa & 58,4 & $87,9 \%$ de la masa total & & \\
Masa muscular & 33,2 & $50 \%$ del peso total & 34 & $-0,8$ \\
Agua corporal total & 42,9 & $64,6 \%$ del peso total & 44,5 & $-1,6$ \\
Agua intracelular & 27 & $40,6 \%$ del peso total & 27,6 & $-0,6$ \\
Agua extracelular & 15,9 & $23,9 \%$ del peso total & 16,9 & -1 \\
\hline
\end{tabular}

En definitiva podemos decir que los resultados del sujeto son muy buenos, ya que está dentro de los parámetros estándar en todos los resultados. Es una persona mayoritariamente musculosa como también nos decía la somatocarta. En la Tabla 9 se puede observar que idealmente debería tener $1,6 \mathrm{~kg}$ de agua corporal más. Esto podría llevar a pensar que el sujeto debería beber en mayor cuantía. Sin embargo, varios análisis de orina de 24 horas han dado como resultado que micciona entorno a los 3 litros diarios, por lo que su ingesta de líquidos debe ser bastante abundante. Este 
estado puede deberse al tratamiento médico que tiene debido a su hipertensión esencial.

\section{- Analítica de sangre:}

Siguiendo a Blas y Vázquez (2000) los resultados obtenidos en la analítica de sangre del sujeto son completamente normales. Al no haber ninguna alteración en los resultados, no podemos prever ningún déficit alimenticio tan significativo como para que tenga consecuencias en la homeostasis sanguínea.

\subsection{Objetivos y planificación de la intervención nutricional}

- Objetivos para el periodo de recuperación:

- Aumentar el peso corporal, priorizando sobre todo en la ganancia de músculo.

- Mantener buenos estados hídricos, puesto que coincide con época de verano.

- Mantener los hábitos alimenticios saludables durante las vacaciones.

- Llegar al periodo de pretemporada en una condición óptima corporal.

- Objetivos para el periodo pretemporada:

- Llegar en un estado de forma ideal para afrontar la temporada.

- Adaptar la ingesta kilocalórica a los nuevos requerimientos.

- Mantener las reservas de glucógeno tras los primeros grandes esfuerzos.

- Establecer una hidratación idónea.

- Aumentar la cantidad de masa magra.

- Objetivos para el periodo competición:

- Llenar las reservas energéticas de cara a los esfuerzos de la competición.

- Mantener la composición corporal.

- Mantener una hidratación idónea, de forma que no sea un condicionante para la competición.

- Facilitar la recuperación tras los esfuerzos de la competición.

- Objetivos para el periodo durante un proceso de lesión:

- Mantener la composición corporal.

- Tratar que los niveles de grasa permanezcan estables.

- Mitigar la perdida masa muscular.

- Tratar de mejorar la recuperación mediante la alimentación garantizando buenos aportes de vitaminas y minerales.

\subsection{Resultados del cuestionario de recuerdo de la dieta de 3 días}

En este apartado se va a analizar el registro de comida durante 3 días, para ello se le pidió al sujeto que anotase minuciosamente las cantidades de los diferentes alimentos que había ingerido (ver resumen en la Tabla 10).

El primer día de registro se obtuvo que la ingesta calórica total fue de 3377 kilocalorías (en adelante Kcal). Respecto a las proteínas ingeridas, han sido $198 \mathrm{~g}$, lo que supone $791 \mathrm{kcal}$ y un $23 \%$ de los macronutrientes totales. En cuanto a los carbohidratos han sido $454 \mathrm{~g}$ ingeridos, lo que por su parte equivale a $1816 \mathrm{kcal}$ y un 
$54 \%$ del total de macronutrientes indigeridos este día. Respecto al aporte de grasas, el sujeto había ingerido uno $86 \mathrm{~g}$, que serían unas $770 \mathrm{kcal}$, lo que supone un porcentaje de macronutrientes de grasas del $23 \%$. En cuanto al tipo de grasa: el $22 \%$ de la ingesta total fue de grasas saturadas, el $31 \%$ monoinsaturadas y el $46 \%$ poliinsaturadas.

Respecto al aporte vitamínico para este primer día de registro, en el caso de las vitaminas $A$, grupo vitamínico $B$ y $C$ había consumido cantidades superiores a las necesarias. Sin embargo, los datos de las vitamina D, E y K fueron inferiores a los requerimientos. Respecto a los minerales: tanto el calcio, como el magnesio, manganeso, fósforo, potasio, selenio, sodio y zinc han sido superiores a la ingesta mínima recomendada.

En el segundo día de registro, la ingesta de kilocalorías totales fue de 3037 $\mathrm{kcal}$. Respecto al aporte de los diferentes macronutrientes encontramos que se han ingeridos $192 \mathrm{~g}$ de proteínas, lo que equivale a $767 \mathrm{kcal}$ y un $25 \%$ de las kcal totales. Respecto a los HC encontramos $379 \mathrm{~g}$, lo que corresponde a $1515 \mathrm{kcal}$ y un $5 \%$ de las kcal totales. Respecto a la ingesta de grasas encontramos que se ha sido de 34 gramos, lo que equivale a $755 \mathrm{kcal}$ y un $2 \%$ del total de éstas. El $3 \%$ de estas grasas fueron saturadas, el $28 \%$ monoinsaturadas y el $41 \%$ poliinsaturada.

En referencia al aporte vitamínico, esta vez sí había cumplido las recomendaciones para las del grupo vitamínico B. Sin embargo, para la mayoría del resto de vitaminas, este día la ingesta fue menor de la recomendada. A lo que minerales se refiere, se han cumplido, al menos, las recomendaciones diarias, superándose en muchos casos.

El tercer y el último día de registro alimenticio, supuso una ingesta de un total de $2689 \mathrm{kcal}$. De estas kilocalorías totales, 546 son de proteína lo que se corresponde con $137 \mathrm{~g}$ y un $20 \%$. El $63 \%$ de las kilocalorías totales han sido de carbohidratos, suponiendo $1705 \mathrm{kcal}$, es decir, $426 \mathrm{~g}$. Y respecto a las grasas, había ingerido $49 \mathrm{~g}$, con una equivalencia de $438 \mathrm{kcal}$ y solo un $16 \%$ de la ingesta total. Además, el $34 \%$ de estas grasas fue saturada, otro $34 \%$ monoinsaturada y un $32 \%$ poliinsaturada.

En referencia a las vitaminas, en esta ocasión superó las recomendaciones diarias para el grupo vitamínico B, vitamina C y vitamina D. Sin embargo, dichas recomendaciones no llegan a cumplirse en el caso de las vitaminas $\mathrm{E}$ y vitaminas $\mathrm{K}$. También cumplió o superó la ingesta referente a todos los minerales.

A continuación, en la Tabla 10 podemos ver un resumen en referencia a la ingesta total de macronutrientes entre los tres días.

Tabla 10. Resumen de la ingesta total de macronutriente en los tres días

\begin{tabular}{ccccc}
\hline & Grasas & Proteínas & HC & Kcal totales por día \\
\cline { 2 - 5 } Día 1 & 770 & 791 & 1816 & 3377 \\
Día 2 & 755 & 767 & 1515 & 3037 \\
Día 3 & 438 & 546 & 1705 & 2689 \\
Total & 1963 & 2104 & 5036 & 9103 \\
\% total & 21,56 & 23,11 & 55,32 & 100 \\
\hline
\end{tabular}


De este registro de la dieta de 3 días se puede extraer el siguiente resultado:

La ingesta kilocalórica total de los tres días con respecto al gasto previsto fue algo superior a la ingesta (203 kcal entre los tres días) como se aprecia en la Tabla 11. Sin embargo, cabe destacar que el registro de la dieta durante 3 días fue realizado durante un período de lesión en el que no se ha hecho actividad física. También es importante recordar que el gasto metabólico total calculado puede estar alterado, en cierta medida, por la enfermedad que padece el sujeto analizado.

Tabla 11. Comparativa entre Kcal ingeridas y gastadas totales

\begin{tabular}{ccc}
\hline Kcal ingeridas totales & Kcal gastadas totales & Diferencia kcal \\
\hline 9103 & $3102,3 \times$ 3días $=9306$ & -203 \\
\hline
\end{tabular}

Teniendo en cuenta las recomendaciones de todos los autores mencionados anteriormente, se ha establecido un criterio propia en cuanto a la división de los macronutrientes en porcentajes, estableciendo un ideal de $20 \%$ de proteínas, $55 \%$ carbohidratos y $25 \%$ de grasas. Según el registro de 3 días analizado, los porcentajes obtenidos están muy cerca del ideal propuesto, sólo con una pequeña desviación de grasas hacia proteínas.

La ingesta de minerales es correcta. Pese a que la de vitaminas no es mala, sí que es mejorable. La mayoría de los grupos vitamínicos se han cubierto de forma eficiente, pero hay déficit en alguno de ellos.

De forma general, este registro mostró que el sujeto no lleva una mala alimentación. Con estos datos obtenidos y teniendo en cuenta las necesidades del deporte, se ha propuesto unos objetivos y dietas lo más acorde posible.

\section{RESULTADOS}

\subsection{Propuesta de dietas}

A continuación se van a proponer 4 dietas distintas según los diferentes periodos del año natural para un deportista, como periodos de lesión, competición, descanso e inicio de la temporada. Cada una de ella va a constar de 7 días y para su realización se van a seguir las recomendaciones de los diferentes autores mencionados en la introducción, además de las preferencias y gustos del usuario. Con estas premisas, se trató de alterar sus hábitos lo menos posible, introduciendo los cambios imprescindibles para cumplir el objetivo. Cabe destacar que se ha observado que el software utilizado para la realización de los menús y su correspondiente aporte kilocalórico dividido en macronutrientes, tiende a aumentar la cantidad de grasas. Se observa como los platos realizados por este programa exceden en el uso de aceites para cocinar, por ejemplo. De la misma forma, las recomendaciones de sodio de la dieta no se corresponde con lo que se le aconseja al usuario, ya que este al padecer de hipertensión arterial debe ingerir la menor cantidad de este mineral posible. Sin embargo, como ocurría con el uso de las grasas, el software utilizado no permite personalizar estos datos. 


\subsubsection{Dieta para el periodo de pretemporada}

El periodo de pretemporada albergó los meses de septiembre y parte de octubre. Durante estos meses las temperaturas fueron altas y si a esto le añadimos los grandes esfuerzos realizados durante la pretemporada, se tuvo especial cuidado con la hidratación. Se trató de aumentar también el aporte kilocalórico debido a que se retoma la actividad física intensa con asiduidad. Con estas premisas se trató de llegar de la mejor forma al calendario competitivo.

Tabla 12. Dieta pretemporada: Primer día (lunes)

\begin{tabular}{|l|c|}
\hline \multicolumn{2}{|c|}{ DESAYUNO } \\
\hline Pan blanco tostado sin sal & $60 \mathrm{~g}$ \\
\hline Aceite de oliva & $10 \mathrm{~g}$ \\
\hline Jamón serrano & $70 \mathrm{~g}$ \\
\hline Tomate & $35 \mathrm{~g}$ \\
\hline Leche de vaca semidesnatada & $250 \mathrm{~g}$ \\
\hline Cacao en polvo azucarado $(2,5 \%$ grasa $)$ & $10 \mathrm{~g}$ \\
\hline Agua & $200 \mathrm{~g}$ \\
\hline
\end{tabular}

\begin{tabular}{|l|c|}
\hline \multicolumn{2}{|c|}{ MEDIA MAÑANA } \\
\hline Almendra sin cáscara & $30 \mathrm{~g}$ \\
\hline Plátano & $200 \mathrm{~g}$ \\
\hline
\end{tabular}

\begin{tabular}{|l|c|}
\hline \multicolumn{2}{|c|}{ MERIENDA } \\
\hline Nueces sin cáscara & $33 \mathrm{~g}$ \\
\hline Pan blanco de molde & $60 \mathrm{~g}$ \\
\hline Margarina & $8 \mathrm{~g}$ \\
\hline Leche de vaca semidesnatada & $250 \mathrm{~g}$ \\
\hline Cacao en polvo azucarado $(2,5 \%$ grasa $)$ & $10 \mathrm{~g}$ \\
\hline
\end{tabular}

\begin{tabular}{|l|c|}
\hline \multicolumn{2}{|c|}{ COMIDA } \\
\hline Lentejas guisadas & 1 rac.-223g \\
\hline Chorizo (21\% grasa) & $10 \mathrm{~g}$ \\
\hline Ternera carne magra & $30 \mathrm{~g}$ \\
\hline Zumo de naranja natural & $220 \mathrm{~g}$ \\
\hline Lechuga & $70 \mathrm{~g}$ \\
\hline Tomate & $35 \mathrm{~g}$ \\
\hline Agua & $600 \mathrm{~g}$ \\
\hline Pan blanco de trigo & $60 \mathrm{~g}$ \\
\hline
\end{tabular}

\begin{tabular}{|l|c|}
\hline \multicolumn{2}{|c|}{ CENA } \\
\hline Boquerones fritos & 1 rac. $291 \mathrm{~g}$ \\
\hline Pasta & $140 \mathrm{~g}$ \\
\hline Pera & $190 \mathrm{~g}$ \\
\hline Agua & $600 \mathrm{~g}$ \\
\hline Queso en lonchas & $20 \mathrm{~g}$ \\
\hline Pan blanco de trigo & $45 \mathrm{~g}$ \\
\hline
\end{tabular}

Tabla 13. Dieta pretemporada: Segundo día (martes)

\begin{tabular}{|l|c|}
\hline \multicolumn{2}{|c|}{ DESAYUNO } \\
\hline Pan blanco tostado & $60 \mathrm{~g}$ \\
\hline Aceite de oliva & $15 \mathrm{~g}$ \\
\hline Tomate & $35 \mathrm{~g}$ \\
\hline Leche de vaca semidesnatada & $250 \mathrm{~g}$ \\
\hline Cacao en polvo azucarado (2,5\% grasa) & $10 \mathrm{~g}$ \\
\hline Agua & $200 \mathrm{~g}$ \\
\hline Jamón cocido (York dulce) & $60 \mathrm{~g}$ \\
\hline Almendra sin cáscara & $20 \mathrm{~g}$ \\
\hline
\end{tabular}

\begin{tabular}{|l|c|}
\hline \multicolumn{2}{|c|}{ MERIENDA } \\
\hline Pan integral de molde & $60 \mathrm{~g}$ \\
\hline Margarina & $8 \mathrm{~g}$ \\
\hline Leche de vaca semidesnatada & $250 \mathrm{~g}$ \\
\hline Cacao en polvo azucarado $(2,5 \%$ grasa $)$ & $10 \mathrm{~g}$ \\
\hline
\end{tabular}

\begin{tabular}{|l|c|}
\hline \multicolumn{2}{|c|}{ MEDIA MAÑANA } \\
\hline Almendra sin cáscara & $25 \mathrm{~g}$ \\
\hline Plátano & $200 \mathrm{~g}$ \\
\hline
\end{tabular}

\begin{tabular}{|l|c|}
\hline \multicolumn{2}{|c|}{ COMIDA } \\
\hline Zumo de naranja natural & $220 \mathrm{~g}$ \\
\hline Agua & $600 \mathrm{~g}$ \\
\hline Lechuga & $65 \mathrm{~g}$ \\
\hline Tomate & $40 \mathrm{~g}$ \\
\hline Arroz con pollo & 1 rac. $-235 \mathrm{~g}$ \\
\hline Pan blanco de trigo sin sal & $65 \mathrm{~g}$ \\
\hline
\end{tabular}

\begin{tabular}{|l|c|}
\hline \multicolumn{2}{|c|}{ CENA } \\
\hline Pera & $190 \mathrm{~g}$ \\
\hline Agua & $600 \mathrm{~g}$ \\
\hline Salmón a la plancha & 1 rac. $-258 \mathrm{~g}$ \\
\hline Ensalada de patatas & 0.8 rac. $-330.4 \mathrm{~g}$ \\
\hline Pan blanco de trigo sin sal & $50 \mathrm{~g}$ \\
\hline
\end{tabular}


Tabla 14. Dieta pretemporada: Tercer día (miércoles)

\begin{tabular}{|l|c|}
\hline \multicolumn{2}{|c|}{ DESAYUNO } \\
\hline Pan blanco tostado & $60 \mathrm{~g}$ \\
\hline Aceite de oliva & $15 \mathrm{~g}$ \\
\hline Tomate & $35 \mathrm{~g}$ \\
\hline Leche de vaca semidesnatada & $250 \mathrm{~g}$ \\
\hline Cacao en polvo azucarado $(2,5 \%$ grasa $)$ & $10 \mathrm{~g}$ \\
\hline Agua & $200 \mathrm{~g}$ \\
\hline Almendra sin cáscara & $20 \mathrm{~g}$ \\
\hline Jamón serrano & $60 \mathrm{~g}$ \\
\hline
\end{tabular}

\begin{tabular}{|l|c|}
\hline \multicolumn{2}{|c|}{ MERIENDA } \\
\hline Pan integral de molde & $60 \mathrm{~g}$ \\
\hline Margarina & $8 \mathrm{~g}$ \\
\hline Leche de vaca semidesnatada & $250 \mathrm{~g}$ \\
\hline Cacao en polvo azucarado (2,5\% grasa) & $10 \mathrm{~g}$ \\
\hline Galletas tipo Maria & $48 \mathrm{~g}$ \\
\hline
\end{tabular}

\begin{tabular}{|l|c|}
\hline \multicolumn{2}{|c|}{ MEDIA MAÑANA } \\
\hline Almendra sin cáscara & $35 \mathrm{~g}$ \\
\hline Plátano & $200 \mathrm{~g}$ \\
\hline
\end{tabular}

\begin{tabular}{|l|c|}
\hline \multicolumn{2}{|c|}{ COMIDA } \\
\hline Zumo de naranja natural & $220 \mathrm{~g}$ \\
\hline Agua & $600 \mathrm{~g}$ \\
\hline Lechuga & $65 \mathrm{~g}$ \\
\hline Tomate & $40 \mathrm{~g}$ \\
\hline Pan blanco de trigo sin sal & $60 \mathrm{~g}$ \\
\hline Potaje de garbanzos & 1.5 rac.-232.5g \\
\hline
\end{tabular}

\begin{tabular}{|l|c|}
\hline \multicolumn{2}{|c|}{ CENA } \\
\hline Agua & $600 \mathrm{~g}$ \\
\hline Pan blanco de trigo sin sal & $50 \mathrm{~g}$ \\
\hline Fresa/ fresón & $170 \mathrm{~g}$ \\
\hline Brécol & $200 \mathrm{~g}$ \\
\hline Huevo frito (1) & 1 rac. $-76 \mathrm{~g}$ \\
\hline Croquetas de carne & 0.8 rac. $-250.4 \mathrm{~g}$ \\
\hline
\end{tabular}

Tabla 15. Dieta pretemporada: Cuarto día dieta (jueves)

\begin{tabular}{|l|c|}
\hline \multicolumn{2}{|c|}{ DESAYUNO } \\
\hline Pan blanco tostado sin sal & $60 \mathrm{~g}$ \\
\hline Aceite de oliva & $10 \mathrm{~g}$ \\
\hline Tomate & $35 \mathrm{~g}$ \\
\hline Leche de vaca semidesnatada & $250 \mathrm{~g}$ \\
\hline Cacao en polvo azucarado (2,5\% grasa) & $10 \mathrm{~g}$ \\
\hline Agua & $200 \mathrm{~g}$ \\
\hline
\end{tabular}

\begin{tabular}{|l|c|}
\hline \multicolumn{2}{|c|}{ MEDIA MAÑANA } \\
\hline Almendra sin cáscara & $30 \mathrm{~g}$ \\
\hline Plátano & $200 \mathrm{~g}$ \\
\hline
\end{tabular}

\begin{tabular}{|l|c|}
\hline \multicolumn{2}{|c|}{ MERIENDA } \\
\hline Pan blanco de molde & $60 \mathrm{~g}$ \\
\hline Margarina & $8 \mathrm{~g}$ \\
\hline Leche de vaca semidesnatada & $250 \mathrm{~g}$ \\
\hline Cacao en polvo azucarado $(2,5 \%$ grasa $)$ & $10 \mathrm{~g}$ \\
\hline Galletas cubiertas de chocolate & $30 \mathrm{~g}$ \\
\hline
\end{tabular}

\begin{tabular}{|l|c|}
\hline \multicolumn{2}{|c|}{ COMIDA } \\
\hline Zumo de naranja natural & $220 \mathrm{~g}$ \\
\hline Lechuga & $70 \mathrm{~g}$ \\
\hline Tomate & $35 \mathrm{~g}$ \\
\hline Agua & $600 \mathrm{~g}$ \\
\hline Pan blanco de trigo & $60 \mathrm{~g}$ \\
\hline Pechuga de pollo empanada & 1rac.-203g \\
\hline Patatas fritas caseras & 1rac.-166g \\
\hline
\end{tabular}

\begin{tabular}{|l|c|}
\hline \multicolumn{2}{|c|}{ CENA } \\
\hline Pera & $190 \mathrm{~g}$ \\
\hline Agua & $600 \mathrm{~g}$ \\
\hline Pan blanco de trigo & $45 \mathrm{~g}$ \\
\hline Lasaña (pasta) & $114 \mathrm{~g}$ \\
\hline Arroz en ensalada con atún & 1 rac. $-241 \mathrm{~g}$ \\
\hline
\end{tabular}


Tabla 16. Dieta pretemporada: Quinto día (viernes)

\begin{tabular}{|l|c|}
\hline \multicolumn{2}{|c|}{ DESAYUNO } \\
\hline Pan blanco tostado sin sal & $60 \mathrm{~g}$ \\
\hline Aceite de oliva & $10 \mathrm{~g}$ \\
\hline Tomate & $35 \mathrm{~g}$ \\
\hline Leche de vaca semidesnatada & $250 \mathrm{~g}$ \\
\hline Cacao en polvo azucarado (2,5\% grasa) & $10 \mathrm{~g}$ \\
\hline Agua & $200 \mathrm{~g}$ \\
\hline
\end{tabular}

\begin{tabular}{|l|c|}
\hline \multicolumn{2}{|c|}{ MEDIA MAÑANA } \\
\hline Almendra sin cáscara & $30 \mathrm{~g}$ \\
\hline Plátano & $200 \mathrm{~g}$ \\
\hline Galletas tipo cookies & $30 \mathrm{~g}$ \\
\hline
\end{tabular}

\begin{tabular}{|l|c|}
\hline \multicolumn{2}{|c|}{ COMIDA } \\
\hline Zumo de naranja natural & $220 \mathrm{~g}$ \\
\hline Lechuga & $70 \mathrm{~g}$ \\
\hline Tomate & $35 \mathrm{~g}$ \\
\hline Agua & $600 \mathrm{~g}$ \\
\hline Pan blanco de trigo & $60 \mathrm{~g}$ \\
\hline Sopa de pasta & 1 rac.-33g \\
\hline Espinacas & $250 \mathrm{~g}$ \\
\hline Croquetas de carne & 1rac.-313g \\
\hline
\end{tabular}

\begin{tabular}{|l|c|}
\hline \multicolumn{2}{|c|}{ MERIENDA } \\
\hline Pan blanco de molde & $60 \mathrm{~g}$ \\
\hline Margarina & $8 \mathrm{~g}$ \\
\hline Leche de vaca semidesnatada & $250 \mathrm{~g}$ \\
\hline Cacao en polvo azucarado $(2,5 \%$ grasa) & $10 \mathrm{~g}$ \\
\hline
\end{tabular}

\begin{tabular}{|l|c|}
\hline \multicolumn{2}{|c|}{ CENA } \\
\hline Agua & $600 \mathrm{~g}$ \\
\hline Pan blanco de trigo & $45 \mathrm{~g}$ \\
\hline Salmón a la plancha & 1 rac.-258g \\
\hline Arroz blanco (guarnición) & 1.5 rac.-97.5g \\
\hline Manzana & $200 \mathrm{~g}$ \\
\hline
\end{tabular}

Tabla 17. Dieta pretemporada: Sexto día (sábado)

\begin{tabular}{|c|c|}
\hline \multicolumn{2}{|l|}{ DESAYUNO } \\
\hline Pan blanco tostado sin sal & $60 \mathrm{~g}$ \\
\hline Leche de vaca semidesnatada & $250 \mathrm{~g}$ \\
\hline Cacao en polvo azucarado ( $2,5 \%$ grasa) & $10 \mathrm{~g}$ \\
\hline Agua & $200 \mathrm{~g}$ \\
\hline Margarina & $8 \mathrm{~g}$ \\
\hline Nueces sin cáscara & $12 \mathrm{~g}$ \\
\hline \multicolumn{2}{|l|}{ MEDIA MAÑANA } \\
\hline Plátano & $200 \mathrm{~g}$ \\
\hline Pera & $190 \mathrm{~g}$ \\
\hline
\end{tabular}

\begin{tabular}{|l|c|}
\hline \multicolumn{2}{|c|}{ MERIENDA } \\
\hline Pan blanco de molde & $60 \mathrm{~g}$ \\
\hline Margarina & $8 \mathrm{~g}$ \\
\hline Leche de vaca semidesnatada & $250 \mathrm{~g}$ \\
\hline Cacao en polvo azucarado $(2,5 \%$ grasa) & $8 \mathrm{~g}$ \\
\hline Galletas cubiertas de chocolate & $50 \mathrm{~g}$ \\
\hline
\end{tabular}

\begin{tabular}{|l|c|}
\hline \multicolumn{2}{|c|}{ COMIDA } \\
\hline Zumo de naranja natural & $220 \mathrm{~g}$ \\
\hline Lechuga & $70 \mathrm{~g}$ \\
\hline Tomate & $35 \mathrm{~g}$ \\
\hline Agua & $600 \mathrm{~g}$ \\
\hline Pan blanco de trigo & $60 \mathrm{~g}$ \\
\hline Cerdo carne magra & $150 \mathrm{~g}$ \\
\hline Ensalada de patatas & 1rac. $413 \mathrm{~g}$ \\
\hline Pechuga de pollo a la plancha & 1rac.-156g \\
\hline
\end{tabular}

\begin{tabular}{|l|c|}
\hline \multicolumn{2}{|c|}{ CENA } \\
\hline Agua & $600 \mathrm{~g}$ \\
\hline Pan blanco de trigo & $60 \mathrm{~g}$ \\
\hline Fresa, fresón & $225 \mathrm{~g}$ \\
\hline Guisantes con jamón & 1 rac.-240g \\
\hline Huevo relleno (1) & 1 rac.-138g \\
\hline
\end{tabular}


Tabla 18. Dieta pretemporada: Séptimo día (domingo)

\begin{tabular}{|l|c|}
\hline \multicolumn{2}{|c|}{ DESAYUNO } \\
\hline Pan blanco tostado sin sal & $60 \mathrm{~g}$ \\
\hline Leche de vaca semidesnatada & $250 \mathrm{~g}$ \\
\hline Cacao en polvo azucarado (2,5\% grasa) & $10 \mathrm{~g}$ \\
\hline Agua & $200 \mathrm{~g}$ \\
\hline Galletas & $48 \mathrm{~g}$ \\
\hline Margarina & $8 \mathrm{~g}$ \\
\hline
\end{tabular}

\begin{tabular}{|l|c|}
\hline \multicolumn{2}{|c|}{ COMIDA } \\
\hline Zumo de naranja natural & $220 \mathrm{~g}$ \\
\hline Lechuga & $70 \mathrm{~g}$ \\
\hline Tomate & $35 \mathrm{~g}$ \\
\hline Agua & $600 \mathrm{~g}$ \\
\hline Pan blanco de trigo & $60 \mathrm{~g}$ \\
\hline Espaguetis & $140 \mathrm{~g}$ \\
\hline Tomate frito & $45 \mathrm{~g}$ \\
\hline
\end{tabular}

\begin{tabular}{|l|c|}
\hline \multicolumn{2}{|c|}{ MERIENDA } \\
\hline Pan blanco de molde & $60 \mathrm{~g}$ \\
\hline Margarina & $8 \mathrm{~g}$ \\
\hline Leche de vaca semidesnatada & $250 \mathrm{~g}$ \\
\hline Cacao en polvo azucarado (2,5\% grasa) & $10 \mathrm{G}$ \\
\hline Galletas tipo Maria & $50 \mathrm{~g}$ \\
\hline
\end{tabular}

\begin{tabular}{|l|c|}
\hline \multicolumn{2}{|c|}{ CENA } \\
\hline Agua & $600 \mathrm{~g}$ \\
\hline Pan blanco de trigo & $60 \mathrm{~g}$ \\
\hline Pimiento rojo & $100 \mathrm{~g}$ \\
\hline Rape & $200 \mathrm{~g}$ \\
\hline Menestra de verduras & 1 rac. $-261 \mathrm{~g}$ \\
\hline Plátano & $200 \mathrm{~g}$ \\
\hline
\end{tabular}


Tabla 19. Resumen semanal dieta de pretemporada

\begin{tabular}{|c|c|c|c|c|c|c|c|c|c|c|c|c|}
\hline & $\begin{array}{l}\text { Día } 1 \\
\text { Lunes }\end{array}$ & $\begin{array}{c}\text { Día } 2 \\
\text { Martes }\end{array}$ & $\begin{array}{c}\text { Día } 3 \\
\text { Miércoles }\end{array}$ & $\begin{array}{c}\text { Día } 4 \\
\text { Jueves }\end{array}$ & $\begin{array}{c}\text { Día } 5 \\
\text { Viernes }\end{array}$ & $\begin{array}{c}\text { Día } 6 \\
\text { Sábado }\end{array}$ & $\begin{array}{c}\text { Día } 7 \\
\text { Domingo }\end{array}$ & Total & Kcal & Media & $\%$ Kcal & \\
\hline \multicolumn{13}{|l|}{ GENERAL } \\
\hline Agua (g) & $2.804,22$ & $2.965,74$ & $2.928,33$ & $2.825,25$ & $2.988,24$ & $3.269,82$ & $2.733,49$ & $20.515,09$ & & $2.930,73$ & & \\
\hline Energía (kcal) & $3.543,58$ & $2.942,14$ & $3.285,36$ & $3.102,15$ & $3.174,11$ & $2.941,49$ & $2.542,09$ & $21.530,92$ & $21.530,92$ & $3.075,85$ & $100 \%$ & \\
\hline Energía (kJ) & $14.825,58$ & $12.304,02$ & $13.739,21$ & $12.974,71$ & $13.274,05$ & $12.302,21$ & $10.629,12$ & $90.048,90$ & & $12.864,13$ & & \\
\hline Proteínas (g) & 161,08 & 120,92 & 140,74 & 108,55 & 118,59 & 134,14 & 92,78 & 876,80 & $3.507,20$ & 125,26 & $16,27 \%$ & \\
\hline Grasa total (g) & 141,51 & 122,05 & 142,05 & 105,07 & 129,63 & 116,02 & 54,47 & 810,80 & $7.297,20$ & 115,83 & $33,86 \%$ & \\
\hline Hidratos de carbono totales (g) & 407,34 & 340,74 & 361,59 & 431,33 & 383,85 & 340,83 & 420,74 & $2.686,42$ & $10.745,68$ & 383,77 & $49,86 \%$ & \\
\hline Azúcares $(\mathrm{g})$ & 116,06 & 114,25 & 125,39 & 124,65 & 126,13 & 144,78 & 135,88 & 887,14 & & 126,73 & & \\
\hline Almidón (g) & 291,33 & 226,62 & 236,25 & 306,77 & 257,81 & 196,23 & 284,88 & $1.799,89$ & & 257,13 & & \\
\hline Fibra dietética (g) & 39,63 & 32,96 & 51,67 & 30,02 & 38,09 & 30,96 & 35,2 & 258,53 & & 36,93 & & \\
\hline Grasa saturada (AGS) (g) & 33,59 & 23,75 & 31,69 & 24,38 & 32,74 & 32,35 & 16,26 & 194,76 & $1.752,84$ & 27,82 & $26,26 \%$ & $8,89 \%$ \\
\hline Grasa monoinsaturada (AGM) (g) & 61,8 & 67,31 & 76,17 & 57,52 & 65,91 & 50,96 & 19,8 & 399,47 & $3.595,23$ & 57,07 & $53,86 \%$ & $18,24 \%$ \\
\hline Grasa poliinsaturada (AGP) (g) & 34,44 & 20,09 & 21,96 & 16,37 & 18,1 & 22,77 & 13,68 & 147,41 & $1.326,69$ & 21,06 & $19,88 \%$ & $6,73 \%$ \\
\hline Colesterol (mg) & 270,5 & 226,45 & 483,53 & 221,39 & 309,45 & 555,37 & 139,48 & $2.206,17$ & & 315,17 & & \\
\hline \multicolumn{13}{|l|}{ MINERALES } \\
\hline Calcio (mg) & $1.334,37$ & $1.120,44$ & $1.527,54$ & $1.117,21$ & $1.444,17$ & $1.159,50$ & $1.171,27$ & $8.874,50$ & & $1.267,79$ & & \\
\hline Hierro (mg) & 26,83 & 16,29 & 27,64 & 16,04 & 23,34 & 19,02 & 17,28 & 146,44 & & 20,92 & & \\
\hline Yodo $(\mu \mathrm{g})$ & 502,37 & 551,61 & 658,56 & 513,06 & 680,5 & 570,11 & 507,53 & $3.983,74$ & & 569,11 & & \\
\hline Magnesio (mg) & 582,25 & 564,87 & 716,74 & 470,35 & 566,43 & 468,94 & 406,58 & $3.776,16$ & & 539,45 & & \\
\hline Cinc (mg) & 15,95 & 12,28 & 14,51 & 10,3 & 12,71 & 13,94 & 9,94 & 89,63 & & 12,80 & & \\
\hline Sodio (mg) & $3.850,19$ & $4.458,82$ & $5.957,91$ & $3.256,94$ & $8.115,62$ & $5.074,59$ & $2.537,26$ & $33.251,33$ & & $4.750,19$ & & \\
\hline Potasio (mg) & $5.298,59$ & $5.681,92$ & $5.607,64$ & $4.890,17$ & $5.003,71$ & $6.247,72$ & $4.195,98$ & $36.925,73$ & & $5.275,10$ & & \\
\hline Fósforo (mg) & $2.328,07$ & 2.149,77 & $2.506,88$ & $1.801,09$ & $2.148,83$ & $1.922,10$ & $1.959,45$ & $14.816,19$ & & $2.116,60$ & & \\
\hline Selenio $(\mu \mathrm{g})$ & 0,00 & 11,38 & 0,00 & 0,00 & 0,00 & 0,29 & 0,00 & 11,67 & & 1,67 & & \\
\hline \multicolumn{13}{|l|}{ VITAMINAS } \\
\hline Tiamina o Vitamina B1 (mg) & 2,43 & 2,12 & 2,3 & 2,03 & 1,85 & 3,16 & 1,84 & 15,73 & & 2,25 & & \\
\hline Riboflavina o Vitamina B2 (mg) & 2,77 & 2,41 & 2,96 & 2,15 & 2,78 & 2,59 & 1,81 & 17,47 & & 2,50 & & \\
\hline Eq. niacina (mg) & 52,71 & 49,1 & 37,68 & 48,26 & 46,7 & 60,11 & 34,62 & 329,18 & & 47,03 & & \\
\hline Vitamina B6 (mg) & 4,64 & 3,98 & 3,02 & 2,8 & 3,52 & 3,72 & 2,02 & 23,70 & & 3,39 & & \\
\hline Ácido fólico ( $\mu \mathrm{g})$ & 385,77 & 399,08 & 697,74 & 391,91 & 631,78 & 400,56 & 406,4 & $3.313,24$ & & 473,32 & & \\
\hline Vitamina B12 $(\mu \mathrm{g})$ & 5,92 & 9,88 & 6,88 & 2,07 & 12 & 7,63 & 3,66 & 48,04 & & 6,86 & & \\
\hline Vitamina C (mg) & 155,23 & 214,65 & 360,66 & 186,43 & 217,59 & 334,57 & 297,07 & $1.766,20$ & & 252,31 & & \\
\hline Vitamina A: Eq. retinol $(\mu \mathrm{g})$ & 676,96 & 399,75 & 742,4 & 303,37 & $1.504,10$ & 440,08 & $1.399,32$ & $5.465,98$ & & 780,85 & & \\
\hline Retinol $(\mu \mathrm{g})$ & 197,25 & 93,78 & 315,87 & 108,73 & 254,33 & 268,68 & 144 & $1.382,64$ & & 197,52 & & \\
\hline Carotenos $(\mu \mathrm{g})$ & $3.188,24$ & $1.804,46$ & $2.505,18$ & $1.120,36$ & $7.450,05$ & 997,18 & $8.136,17$ & $25.201,64$ & & $3.600,23$ & & \\
\hline Vitamina D $(\mu \mathrm{g})$ & 14,04 & 13,4 & 1,44 & 0,88 & 13,91 & 1,23 & 0 & 44,90 & & 6,41 & & \\
\hline Vitamina E (mg) & 10,29 & 19,01 & 21,57 & 12,29 & 18,64 & 7,34 & 4,05 & 93,19 & & 13,31 & & \\
\hline \multicolumn{13}{|l|}{ ÁCIDOS GRASOS } \\
\hline Grasa total (g) & 141,51 & 122,05 & 142,05 & 105,07 & 129,63 & 116,02 & 54,47 & 810,80 & & 115,83 & & \\
\hline Grasa saturada (AGS) (g) & 33,59 & 23,75 & 31,69 & 24,38 & 32,74 & 32,35 & 16,26 & 194,76 & & 27,82 & & \\
\hline Grasa monoinsaturada (AGM) (g) & 61,8 & 67,31 & 76,17 & 57,52 & 65,91 & 50,96 & 19,8 & 399,47 & & 57,07 & & \\
\hline Grasa poliinsaturada (AGP) (g) & 34,44 & 20,09 & 21,96 & 16,37 & 18,1 & 22,77 & 13,68 & 147,41 & & 21,06 & & \\
\hline Colesterol (mg) & 270,5 & 226,45 & 483,53 & 221,39 & 309,45 & 555,37 & 139,48 & $2.206,17$ & & 315,17 & & \\
\hline C12:0 (g) - Ac. láurico - Ac. dodecanoico & 0,67 & 0,42 & 0,7 & 0,41 & 0,81 & 0,62 & 0,93 & 4,56 & &, 65 & & \\
\hline C14:0 (g) - Ac. mirístico - Ac. tetradecanoico & 2,67 & 1,85 & 1,98 & 0,86 & 3,08 & 1,12 & 1,12 & 12,68 & & 1,81 & & \\
\hline C16:0 (g) - Ac. palmítico - Ac. hexadecanoico & 24,33 & 15,11 & 19,26 & 12,67 & 19,81 & 14,8 & 8,77 & 114,75 & & 16,39 & & \\
\hline C18:0 (g) - Ac. esteárico - Ac. octadecanoico & 11,47 & 4,68 & 6,83 & 3,83 & 6,25 & 5,58 & 3,98 & 42,62 & & 6,09 & & \\
\hline C18:1 (g) - Ac. oleico - Ac. octadecenoico & 60,78 & 59,87 & 73,6 & 53,49 & 58,41 & 44,9 & 18,79 & 369,84 & & 52,83 & & \\
\hline C18:2 (g) - Ac. linoleico - Ac. octadecadienoico & 26,09 & 16,2 & 19,71 & 14,57 & 14,18 & 19,73 & 12,13 & 122,61 & & 17,52 & & \\
\hline C18:3 (g) - Ac. a-linolã $@$ nico - Ac. octadecatrienoico & 3,18 & 1,14 & 1,05 & 0,94 & 1,27 & 1,85 & 0,71 & 10,14 & & 1,45 & & \\
\hline C20:4 (g) - Ac. araquidónico - Ac. eicosatetraenoico & 0,07 & 0,11 & 0,05 & 0,02 & 0,07 & 0,08 & 0,01 & 0,41 & &, 06 & & \\
\hline C20:5 (g) - EPA - Ac. eicosapentaenoico & 1,23 & 0,79 & 0,03 & 0,05 & 0,79 & 0 & 0 & 2,89 & & ,41 & & \\
\hline C22:6 (g) - DHA - Ac. docosahexaenoico & 2,1 & 1,32 & 0,05 & 0,08 & 1,32 & 0,01 & 0 & 4,88 & & ,70 & & \\
\hline Ácidos grasos cis (g) & 53,83 & 57,91 & 63,04 & 52,12 & 64,85 & 46,74 & 28,24 & 366,73 & & 52,39 & & \\
\hline
\end{tabular}




\subsubsection{Dieta para el periodo de competición}

Como periodo de competición se consideraron todos los meses en los que se iba a englobar la fase regular, desde mediados de octubre hasta marzo, con posibilidad de extenderse hasta principios de mayo. Como se presentaban en los objetivos para esta fase, se trató que la alimentación no fuese un condicionante del rendimiento, sino, más bien un factor que permitiese al deportista competir de la mejor forma. Para ello, los días previos al partido y el día propio del partido se aumentaron las ingestas de HC y cuidaremos especialmente la hidratación y el aporte de vitaminas y minerales.

Tabla 20. Dieta en periodo de competición: Primer día (lunes)

\begin{tabular}{|c|c|}
\hline \multicolumn{2}{|l|}{ DESAYUNO } \\
\hline Pan blanco de trigo sin sal & $70 \mathrm{~g}$ \\
\hline Tomate & $30 \mathrm{~g}$ \\
\hline Leche de vaca semidesnatada & $250 \mathrm{~g}$ \\
\hline Cacao en polvo azucarado ( $2,5 \%$ grasa) & $10 \mathrm{~g}$ \\
\hline Agua & $200 \mathrm{~g}$ \\
\hline Aceite de oliva & $10 \mathrm{~g}$ \\
\hline \multicolumn{2}{|l|}{ MEDIA MAÑANA } \\
\hline Kiwi & $100 \mathrm{~g}$ \\
\hline Batido de cacao & $200 \mathrm{~g}$ \\
\hline Pera en almíbar & $150 \mathrm{~g}$ \\
\hline Agua & $200 \mathrm{~g}$ \\
\hline \multicolumn{2}{|l|}{ COMIDA } \\
\hline Atún & $180 \mathrm{~g}$ \\
\hline Ensalada de patatas & 1rac. $-413 \mathrm{~g}$ \\
\hline Pan blanco de trigo sin sal & $75 \mathrm{~g}$ \\
\hline Lechuga & $80 \mathrm{~g}$ \\
\hline Tomate & $40 \mathrm{~g}$ \\
\hline Cebolla & $15 \mathrm{~g}$ \\
\hline Agua & $600 \mathrm{~g}$ \\
\hline Manzana & $120 \mathrm{~g}$ \\
\hline
\end{tabular}

\begin{tabular}{|l|c|}
\hline \multicolumn{2}{|c|}{ MERIENDA } \\
\hline Cereales de desayuno & $30 \mathrm{~g}$ \\
\hline Pan blanco tostado & $60 \mathrm{~g}$ \\
\hline Margarina & $16 \mathrm{~g}$ \\
\hline Leche de vaca semidesnatada & $250 \mathrm{~g}$ \\
\hline Cacao en polvo azucarado (2,5\% grasa) & $10 \mathrm{~g}$ \\
\hline \multicolumn{2}{|c|}{ CENA } \\
\hline \multicolumn{2}{|c|}{} \\
\hline Habas secas & $100 \mathrm{~g}$ \\
\hline Huevo frito (1) & 1.32 rac. $-100.32 \mathrm{~g}$ \\
\hline Sardinas a la plancha con ensalada & 1.3 rac. $-283.4 \mathrm{~g}$ \\
\hline Plátano & $120 \mathrm{~g}$ \\
\hline Fresa & fresón \\
\hline Champiñón & $65 \mathrm{~g}$ \\
\hline Agua & $400 \mathrm{~g}$ \\
\hline
\end{tabular}

Tabla 21. Dieta en periodo de competición: Segundo día (martes)

\begin{tabular}{|c|c|}
\hline \multicolumn{2}{|l|}{ DESAYUNO } \\
\hline Pan blanco de trigo sin sal & $70 \mathrm{~g}$ \\
\hline Tomate & $30 \mathrm{~g}$ \\
\hline Leche de vaca semidesnatada & $250 \mathrm{~g}$ \\
\hline Cacao en polvo azucarado ( $2,5 \%$ grasa) & $10 \mathrm{~g}$ \\
\hline Agua & $200 \mathrm{~g}$ \\
\hline Margarina & $10 \mathrm{~g}$ \\
\hline \multicolumn{2}{|l|}{ MEDIA MAÑANA } \\
\hline Batido de fresa & 1rac. $-360 \mathrm{~g}$ \\
\hline Nueces sin cáscara & $12 \mathrm{~g}$ \\
\hline \multicolumn{2}{|l|}{ COMIDA } \\
\hline Pan blanco de trigo sin sal & $75 g$ \\
\hline Lechuga & $80 \mathrm{~g}$ \\
\hline Tomate & $40 \mathrm{~g}$ \\
\hline Cebolla & $15 g$ \\
\hline Agua & $600 \mathrm{~g}$ \\
\hline Judias blancas, judias pintas & $140 \mathrm{~g}$ \\
\hline Calabaza & $30 \mathrm{~g}$ \\
\hline Bacalao fresco & $60 \mathrm{~g}$ \\
\hline Chorizo (21\% grasa) & $25 g$ \\
\hline Piña & $160 \mathrm{~g}$ \\
\hline
\end{tabular}

\begin{tabular}{|l|c|}
\hline \multicolumn{2}{|c|}{ MERIENDA } \\
\hline Cereales de desayuno & $30 \mathrm{~g}$ \\
\hline Pan blanco tostado & $70 \mathrm{~g}$ \\
\hline Margarina & $16 \mathrm{~g}$ \\
\hline Leche de vaca semidesnatada & $250 \mathrm{~g}$ \\
\hline Cacao en polvo azucarado $(2,5 \%$ grasa $)$ & $10 \mathrm{~g}$ \\
\hline
\end{tabular}

\begin{tabular}{|l|c|}
\hline \multicolumn{2}{|c|}{ CENA } \\
\hline Agua & $400 \mathrm{~g}$ \\
\hline Patatas con rape & $1.3 \mathrm{rac} .-423.8 \mathrm{~g}$ \\
\hline Plátano & $200 \mathrm{~g}$ \\
\hline Pisto & $1 \mathrm{rac} .-228 \mathrm{~g}$ \\
\hline
\end{tabular}


Tabla 22. Dieta en periodo de competición: Tercer día (miércoles)

\begin{tabular}{|l|c|}
\hline \multicolumn{2}{|c|}{ DESAYUNO } \\
\hline Leche de vaca semidesnatada & $250 \mathrm{~g}$ \\
\hline Cacao en polvo azucarado $(2,5 \%$ grasa) & $10 \mathrm{~g}$ \\
\hline Pan blanco tostado sin sal & $70 \mathrm{~g}$ \\
\hline Margarina & $10 \mathrm{~g}$ \\
\hline Agua & $200 \mathrm{~g}$ \\
\hline Galletas tipo Maria & $42 \mathrm{~g}$ \\
\hline
\end{tabular}

\begin{tabular}{|l|c|}
\hline \multicolumn{2}{|c|}{ MEDIA MAÑANA } \\
\hline Bocadillo de jamón de York & 1 rac.-160g \\
\hline Zumo de naranja natural & $200 \mathrm{~g}$ \\
\hline
\end{tabular}

\begin{tabular}{|l|c|}
\hline \multicolumn{2}{|c|}{ MERIENDA } \\
\hline Leche de vaca semidesnatada & $250 \mathrm{~g}$ \\
\hline Cacao en polvo azucarado (2,5\% grasa) & $10 \mathrm{~g}$ \\
\hline Pan blanco tostado sin sal & $60 \mathrm{~g}$ \\
\hline Margarina & $10 \mathrm{~g}$ \\
\hline Cereales de desayuno & $25 \mathrm{~g}$ \\
\hline
\end{tabular}

\begin{tabular}{|l|c|}
\hline \multicolumn{2}{|c|}{ COMIDA } \\
\hline Arroz blanco con tomate & $1.75 \mathrm{rac} .227 .5 \mathrm{~g}$ \\
\hline Tomate & $30 \mathrm{~g}$ \\
\hline Cebolla & $12 \mathrm{~g}$ \\
\hline Plátano & $200 \mathrm{~g}$ \\
\hline Lechuga & $70 \mathrm{~g}$ \\
\hline Agua & $600 \mathrm{~g}$ \\
\hline
\end{tabular}

\begin{tabular}{|l|c|}
\hline \multicolumn{2}{|c|}{ CENA } \\
\hline Boquerones fritos & 1rac.-291g \\
\hline Huevos (2) revueltos con setas y gambas & 1 rac.-203g \\
\hline Agua & $400 \mathrm{~g}$ \\
\hline Pera & $190 \mathrm{~g}$ \\
\hline
\end{tabular}

Tabla 23. Dieta en periodo de competición: Cuarto día (jueves)

\begin{tabular}{|l|c|}
\hline \multicolumn{2}{|c|}{ DESAYUNO } \\
\hline Leche de vaca semidesnatada & $250 \mathrm{~g}$ \\
\hline Cacao en polvo azucarado (2,5\% grasa) & $10 \mathrm{~g}$ \\
\hline Pan blanco tostado sin sal & $70 \mathrm{~g}$ \\
\hline Margarina & $10 \mathrm{~g}$ \\
\hline Agua & $200 \mathrm{~g}$ \\
\hline Cereales de desayuno & $30 \mathrm{~g}$ \\
\hline
\end{tabular}

\begin{tabular}{|l|c|}
\hline \multicolumn{2}{|c|}{ MEDIA MAÑANA } \\
\hline Plátano & $200 \mathrm{~g}$ \\
\hline Kiwi & $100 \mathrm{~g}$ \\
\hline Batido con queso & 1 rac.-260g \\
\hline
\end{tabular}

\begin{tabular}{|l|c|}
\hline \multicolumn{2}{|c|}{ MERIENDA } \\
\hline Leche de vaca semidesnatada & $250 \mathrm{~g}$ \\
\hline Cacao en polvo azucarado (2,5\% grasa & $10 \mathrm{~g}$ \\
\hline Pan blanco tostado sin sal & $60 \mathrm{~g}$ \\
\hline Margarina & $10 \mathrm{~g}$ \\
\hline Agua & $200 \mathrm{~g}$ \\
\hline Galletas & $40 \mathrm{~g}$ \\
\hline
\end{tabular}

\begin{tabular}{|l|c|}
\hline \multicolumn{2}{|c|}{ COMIDA } \\
\hline Tomate & $30 \mathrm{~g}$ \\
\hline Cebolla & $12 \mathrm{~g}$ \\
\hline Lechuga & $70 \mathrm{~g}$ \\
\hline Agua & $600 \mathrm{~g}$ \\
\hline Naranja & $225 \mathrm{~g}$ \\
\hline Espinacas a la catalana & 1 rac. $-336 \mathrm{~g}$ \\
\hline Pollo pechuga & $220 \mathrm{~g}$ \\
\hline
\end{tabular}

\begin{tabular}{|l|c|}
\hline \multicolumn{2}{|c|}{ CENA } \\
\hline Agua & $400 \mathrm{~g}$ \\
\hline Pera & $190 \mathrm{~g}$ \\
\hline Patatas con bacalao & 1 rac. $-240 \mathrm{~g}$ \\
\hline Lasaña (pasta) & $95 \mathrm{~g}$ \\
\hline
\end{tabular}


Tabla 24. Dieta en periodo de competición: Quinto día (viernes)

\begin{tabular}{|l|c|}
\hline \multicolumn{2}{|c|}{ DESAYUNO } \\
\hline Pan blanco tostado sin sal & $70 \mathrm{~g}$ \\
\hline Margarina & $10 \mathrm{~g}$ \\
\hline Cacao en polvo azucarado (2,5\% grasa) & $10 \mathrm{~g}$ \\
\hline Galletas tipo Maria & $30 \mathrm{~g}$ \\
\hline Agua & $200 \mathrm{~g}$ \\
\hline Leche de vaca desnatada & $250 \mathrm{~g}$ \\
\hline
\end{tabular}

\begin{tabular}{|l|c|}
\hline \multicolumn{2}{|c|}{ MERIENDA } \\
\hline Leche de vaca desnatada & $250 \mathrm{~g}$ \\
\hline Pan blanco tostado sin sal & $60 \mathrm{~g}$ \\
\hline Margarina & $10 \mathrm{~g}$ \\
\hline Cacao en polvo azucarado (2,5\% grasa) & $10 \mathrm{~g}$ \\
\hline Agua & $300 \mathrm{~g}$ \\
\hline
\end{tabular}

\begin{tabular}{|l|l|}
\hline \multicolumn{2}{|c|}{ MEDIA MAÑANA } \\
\hline Pasta al huevo hervida & $120 \mathrm{~g}$ \\
\hline Zumo de naranja natural & $200 \mathrm{~g}$ \\
\hline Agua & $200 \mathrm{~g}$ \\
\hline
\end{tabular}

\begin{tabular}{|l|c|}
\hline \multicolumn{2}{|c|}{ COMIDA } \\
\hline Tortilla de patata & 1rac.-283g \\
\hline Arroz con pollo & 1.5 rac.- $352.5 \mathrm{~g}$ \\
\hline Plátano & $200 \mathrm{~g}$ \\
\hline Pan blanco de trigo sin sal & $65 \mathrm{~g}$ \\
\hline Agua & $600 \mathrm{~g}$ \\
\hline
\end{tabular}

\begin{tabular}{|l|c|}
\hline \multicolumn{2}{|c|}{ CENA } \\
\hline Lechuga & $100 \mathrm{~g}$ \\
\hline Tomate & $45 \mathrm{~g}$ \\
\hline Cebolla & $20 \mathrm{~g}$ \\
\hline Maíz desgranado en conserva & $30 \mathrm{~g}$ \\
\hline Atún & $30 \mathrm{~g}$ \\
\hline Macarrones al ajillo & 1.5 rac.-127.5g \\
\hline Pan blanco de trigo sin sal & $50 \mathrm{~g}$ \\
\hline Agua & $400 \mathrm{~g}$ \\
\hline
\end{tabular}

Tabla 25. Dieta en periodo de competición: Sexto día (sábado)

\begin{tabular}{|l|c|}
\hline \multicolumn{2}{|c|}{ DESAYUNO } \\
\hline Agua & $300 \mathrm{~g}$ \\
\hline Zumo de naranja & $200 \mathrm{~g}$ \\
\hline Limón & $80 \mathrm{~g}$ \\
\hline Pechuga de pollo a la plancha & 0.7 rac. $-109.2 \mathrm{~g}$ \\
\hline Arroz con verduras & 1 rac.-216g \\
\hline Pan blanco de trigo sin sal & $50 \mathrm{~g}$ \\
\hline
\end{tabular}

\begin{tabular}{|l|l|}
\hline \multicolumn{2}{|c|}{ MERIENDA } \\
\hline Agua & $300 \mathrm{~g}$ \\
\hline Plátano & $200 \mathrm{~g}$ \\
\hline
\end{tabular}

\begin{tabular}{|l|c|}
\hline \multicolumn{2}{|c|}{ COMIDA } \\
\hline Pan blanco de trigo sin sal & $65 \mathrm{~g}$ \\
\hline Agua & $600 \mathrm{~g}$ \\
\hline Macarrones con tomate & $1.5 \mathrm{rac} .-271.5 \mathrm{~g}$ \\
\hline Kiwi & $100 \mathrm{~g}$ \\
\hline Clara de huevo & $38 \mathrm{~g}$ \\
\hline Ensalada de patatas & $0.5 \mathrm{rac} .-206.5 \mathrm{~g}$ \\
\hline
\end{tabular}

\begin{tabular}{|l|l|}
\hline \multicolumn{2}{|c|}{ MERIENDA } \\
\hline Agua & $300 \mathrm{~g}$ \\
\hline Plátano & $200 \mathrm{~g}$ \\
\hline
\end{tabular}

\begin{tabular}{|l|c|}
\hline \multicolumn{2}{|c|}{ CENA } \\
\hline Lechuga & $100 \mathrm{~g}$ \\
\hline Tomate & $45 \mathrm{~g}$ \\
\hline Cebolla & $20 \mathrm{~g}$ \\
\hline Pan blanco de trigo sin sal & $50 \mathrm{~g}$ \\
\hline Agua & $400 \mathrm{~g}$ \\
\hline Guisantes con calamares & 1 rac. $-313 \mathrm{~g}$ \\
\hline Canelones (pasta) & $100 \mathrm{~g}$ \\
\hline Maiz desgranado en conserva & $60 \mathrm{~g}$ \\
\hline Pisto & 1 rac.-228g \\
\hline
\end{tabular}


Tabla 26. Dieta en periodo de competición: Séptimo día (domingo)

\begin{tabular}{|l|c|}
\hline \multicolumn{2}{|c|}{ DESAYUNO } \\
\hline Agua & $300 \mathrm{~g}$ \\
\hline Leche de vaca desnatada & $250 \mathrm{~g}$ \\
\hline Cereales de desayuno & $30 \mathrm{~g}$ \\
\hline Pan blanco tostado sin sal & $60 \mathrm{~g}$ \\
\hline Margarina & $10 \mathrm{~g}$ \\
\hline Cacao en polvo azucarado (2,5\% grasa) & $10 \mathrm{~g}$ \\
\hline
\end{tabular}

\begin{tabular}{|l|c|}
\hline \multicolumn{2}{|c|}{ MERIENDA } \\
\hline Leche de vaca desnatada & $250 \mathrm{~g}$ \\
\hline Choco krispies (Kellogg's) & $60 \mathrm{~g}$ \\
\hline Bollo con crema de cacao & $60 \mathrm{~g}$ \\
\hline
\end{tabular}

\begin{tabular}{|l|c|}
\hline \multicolumn{2}{|c|}{ MEDIA MAÑANA } \\
\hline Pechuga de pollo a la plancha & 1 rac.-156g \\
\hline Agua & $200 \mathrm{~g}$ \\
\hline
\end{tabular}

\begin{tabular}{|l|c|}
\hline \multicolumn{2}{|c|}{ COMIDA } \\
\hline Pan blanco de trigo sin sal & $65 \mathrm{~g}$ \\
\hline Agua & $600 \mathrm{~g}$ \\
\hline Gazpacho & 1 rac.-233g \\
\hline Tortilla de patata & 1 rac.-283g \\
\hline Espaguetis & $70 \mathrm{~g}$ \\
\hline Tomate frito & $30 \mathrm{~g}$ \\
\hline Naranja & $225 \mathrm{~g}$ \\
\hline
\end{tabular}

\begin{tabular}{|l|c|}
\hline \multicolumn{2}{|c|}{ CENA } \\
\hline Lechuga & $100 \mathrm{~g}$ \\
\hline Tomate & $45 \mathrm{~g}$ \\
\hline Cebolla & $20 \mathrm{~g}$ \\
\hline Pan blanco de trigo sin sal & $50 \mathrm{~g}$ \\
\hline Agua & $400 \mathrm{~g}$ \\
\hline Arroz con pollo & $1 \mathrm{rac} .-235 \mathrm{~g}$ \\
\hline Fresa fresón & $200 \mathrm{~g}$ \\
\hline
\end{tabular}


Tabla 27. Resumen semanal dieta de competición

\begin{tabular}{|c|c|c|c|c|c|c|c|c|c|c|c|}
\hline \multirow{2}{*}{\multicolumn{12}{|c|}{ Viernes Sabado Domingo }} \\
\hline & & & & & & & & & & & \\
\hline Agua (g) & $3.373,36$ & $2.835,25$ & $2.832,46$ & $3.185,47$ & $3.081,65$ & $3.103,20$ & $3.121,91$ & $21.533,30$ & & $3.076,19$ & \\
\hline Energía (kcal) & $3.279,56$ & $2.914,61$ & $3.197,86$ & $3.044,58$ & $3.252,04$ & $3.143,14$ & $3.153,91$ & $21.985,70$ & $21.985,70$ & $3.140,81$ & $100 \%$ \\
\hline Energía (kJ) & $13.718,72$ & 12. 188,14 & $13.374,93$ & $12.735,07$ & $13.603,71$ & $13.153,25$ & $13.197,74$ & $91.971,56$ & & $13.138,79$ & \\
\hline Proteínas (g) & 146,83 & 116,6 & 122,59 & 138,25 & 113,9 & 129,55 & 121,72 & 889,44 & $3.557,76$ & 127,06 & $16,19 \%$ \\
\hline Grasa total (g) & 125,85 & 92,42 & 121,19 & 105,89 & 94,99 & 99,63 & 91,8 & 731,77 & $6.585,93$ & 104,54 & $29,97 \%$ \\
\hline Hidratos de carbono totales (g) & 390,63 & 401,83 & 405,14 & 385,48 & 485,29 & 429,98 & 460,33 & $2.958,68$ & $11.834,72$ & 422,67 & $53,85 \%$ \\
\hline Azúcares (g) & 151,12 & 129,71 & 120,88 & 173,54 & 110,81 & 97,19 & 127,6 & 910,85 & & 130,12 & \\
\hline Almidón (g) & 239,74 & 272,25 & 284,26 & 212,07 & 374,58 & 332,85 & 332,81 & $2.048,56$ & & 292,65 & \\
\hline Fibra dietética (g) & 48,97 & 62,54 & 24,21 & 45,35 & 27,46 & 45,29 & 35,14 & 288,96 & & 41,28 & \\
\hline Grasa saturada (AGS) (g) & 32,51 & 21,68 & 29,7 & 26,95 & 20,68 & 22,64 & 18,44 & 172,60 & $1.553,40$ & 24,66 & $7,72 \%$ \\
\hline Grasa monoinsaturada (AGM) (g) & 54,91 & 39,4 & 55,48 & 40,43 & 47,14 & 55,66 & 45,75 & 338,77 & $3.048,93$ & 48,40 & $15,15 \%$ \\
\hline Grasa poliinsaturada (AGP) (g) & 24,41 & 22,85 & 26,03 & 29,81 & 20,09 & 15,03 & 20,35 & 158,57 & $1.427,13$ & 22,65 & $7,09 \%$ \\
\hline Colesterol (mg) & 517,49 & 126,61 & 728,77 & 283,41 & 408,81 & 329 & 452,22 & $2.846,31$ & & 406,62 & \\
\hline \multicolumn{12}{|l|}{ MINERALES } \\
\hline Calcio (mg) & $1.436,92$ & $1.523,46$ & $1.158,06$ & $1.594,37$ & $1.055,02$ & 816,74 & $1.361,19$ & $8.945,76$ & & $1.277,97$ & \\
\hline Hierro (mg) & 28,66 & 27,85 & 18,31 & 26,85 & 16,74 & 20,87 & 25,59 & 164,87 & & 23,55 & \\
\hline Yodo $(\mu \mathrm{g})$ & 596,72 & 717,5 & 597,22 & 697,81 & 540,79 & 132,78 & 555,3 & $3.838,12$ & & 548,30 & \\
\hline Magnesio (mg) & 589,76 & 635,9 & 378,29 & 615,17 & 418,37 & 523,4 & 442,04 & $3.602,93$ & & 514,70 & \\
\hline Cinc $(\mathrm{mg})$ & 14,86 & 14,44 & 11,39 & 12,12 & 10,73 & 15,23 & 11,67 & 90,44 & & 12,92 & \\
\hline Sodio (mg) & $4.812,31$ & $3.719,83$ & $5.411,01$ & $3.266,39$ & $3.373,58$ & $4.771,17$ & $4.024,10$ & $29.378,39$ & & $4.196,91$ & \\
\hline Potasio (mg) & $6.545,44$ & $6.665,67$ & $4.091,62$ & $6.472,86$ & $4.345,19$ & $5.433,86$ & $5.051,06$ & $38.605,70$ & & $5.515,10$ & \\
\hline Fósforo (mg) & $2.946,24$ & $2.335,81$ & $1.893,80$ & $2.477,17$ & $1.900,30$ & $1.829,44$ & $1.772,48$ & $15.155,24$ & & $2.165,03$ & \\
\hline Selenio $(\mu \mathrm{g})$ & 138,74 & 0,00 & 0,00 & 0,00 & 40,2 & 0 & 11,38 & 190,32 & & 27,19 & \\
\hline \multicolumn{12}{|l|}{ VITAMINAS } \\
\hline Tiamina o Vitamina B1 (mg) & 2,39 & 2,74 & 2,04 & 2,67 & 1,68 & 2,4 & 2,68 & 16,60 & & 2,37 & \\
\hline Riboflavina o Vitamina B2 (mg) & 3,76 & 2,94 & 3,15 & 3,2 & 2,05 & 1,56 & 3,32 & 19,98 & & 2,85 & \\
\hline Eq. niacina $(\mathrm{mg})$ & 70,15 & 42,92 & 46,41 & 62,91 & 45,01 & 54,84 & 65,87 & 388,11 & & 55,44 & \\
\hline Vitamina B6 (mg) & 4,37 & 4,07 & 4,44 & 3,9 & 2,87 & 3,24 & 4,64 & 27,53 & & 3,93 & \\
\hline Ácido fólico $(\mu \mathrm{g})$ & 379,27 & 341,14 & 380,8 & 629,79 & 344,7 & 481,92 & 554,34 & $3.111,96$ & & 444,57 & \\
\hline Vitamina B12 $(\mu \mathrm{g})$ & 20,21 & 4,4 & 8,17 & 4,43 & 4,45 & 2,24 & 3,69 & 47,59 & & 6,80 & \\
\hline Vitamina C (mg) & 297,64 & 233,15 & 132,45 & 270,84 & 186,25 & 350,05 & 349,03 & $1.819,41$ & & 259,92 & \\
\hline Vitamina A: Eq. retinol $(\mu \mathrm{g})$ & 799,1 & 606,92 & 684,83 & $1.613,88$ & 621,29 & 989,65 & 607,29 & $5.922,96$ & & 846,14 & \\
\hline Retinol ( $\mu \mathrm{g})$ & 500,75 & 238,5 & 485,36 & 271,25 & 310,4 & 70 & 198,68 & $2.074,94$ & & 296,42 & \\
\hline Carotenos $(\mu \mathrm{g})$ & $1.542,80$ & $2.160,12$ & $1.160,92$ & $8.337,11$ & $1.878,68$ & $4.879,39$ & $2.718,27$ & $22.677,29$ & & $3.239,61$ & \\
\hline Vitamina D ( $\mu \mathrm{g})$ & 52,59 & 2,69 & 17,11 & 1,32 & 8,92 & 0,14 & 4,81 & 87,58 & & 12,51 & \\
\hline Vitamina $\mathrm{E}(\mathrm{mg})$ & 10,97 & 10,07 & 7,35 & 13,64 & 7,16 & 10,26 & 10,32 & 69,77 & & 9,97 & \\
\hline \multicolumn{12}{|l|}{ ACIDOS GRASOS } \\
\hline Grasa total (g) & 125,85 & 92,42 & 121,19 & 105,89 & 94,99 & 99,63 & 91,8 & 731,77 & & 104,54 & \\
\hline Grasa saturada (AGS) (g) & 32,51 & 21,68 & 29,7 & 26,95 & 20,68 & 22,64 & 18,44 & 172,60 & & 24,66 & \\
\hline Grasa monoinsaturada (AGM) (g) & 54,91 & 39,4 & 55,48 & 40,43 & 47,14 & 55,66 & 45,75 & 338,77 & & 48,40 & \\
\hline Grasa poliinsaturada (AGP) (g) & 24,41 & 22,85 & 26,03 & 29,81 & 20,09 & 15,03 & 20,35 & 158,57 & & 22,65 & \\
\hline Colesterol (mg) & 517,49 & 126,61 & 728,77 & 283,41 & 408,81 & 329 & 452,22 & $2.846,31$ & & 406,62 & \\
\hline C12:0 (g) - Ac. láurico - Ac. dodecanoico & 0,61 & 0,83 & 0,72 & 1,3 & 0,5 & 0,01 & 0,26 & 4,23 & & 0,60 & \\
\hline C14:0 (g) - Ac. mirístico - Ac. tetradecanoico & 1,74 & 1,2 & 1,81 & 2,26 & 0,39 & 0,29 & 0,27 & 7,96 & & 1,14 & \\
\hline C16:0 (g) - Ac. palmítico - Ac. hexadecanoico & 19,58 & 12,29 & 17,89 & 13,87 & 13,27 & 12,15 & 11,75 & 100,80 & & 14,40 & \\
\hline C18:0 (g) - Ac. esteárico - Ac. octadecanoico & 7,14 & 5,2 & 6,8 & 5,38 & 4,47 & 3,53 & 3,78 & 36,30 & & 5,19 & \\
\hline C18:1 (g) - Ac. oleico - Ac. octadecenoico & 52,12 & 37,87 & 52,53 & 31,54 & 44,38 & 53,06 & 43,88 & 315,38 & & 45,05 & \\
\hline C18:2 (g) - Ac. linoleico - Ac. octadecadienoico & 14 & 20,43 & 20,52 & 13,57 & 16,85 & 12,73 & 18,8 & 116,90 & & 16,70 & \\
\hline C18:3 (g) - Ac. a-linolénico - Ac. octadecatrienoico & 1,43 & 1,71 & 1,31 & 1,3 & 1,21 & 0,82 & 0,98 & 8,76 & & 1,25 & \\
\hline C20:4 (g) - Ac. araquidónico - Ac. eicosatetraenoico & 0,21 & 0,05 & 0,07 & 0,03 & 0,07 & 0,04 & 0,04 & 0,51 & & 0,07 & \\
\hline C20:5 (g) - EPA - Ac. eicosapentaenoico & 1,58 & 0,03 & 1,28 & 0,02 & 0,19 & 0,14 & 0 & 3,24 & & 0,46 & \\
\hline C22:6 (g) - DHA - Ac. docosahexaenoico & 4,87 & 0,05 & 2,14 & 0,04 & 0,62 & 0,33 & 0 & 8,05 & & 1,15 & \\
\hline Ácidos grasos cis (g) & 63,01 & 45,71 & 70,02 & 43,08 & 59,55 & 61,95 & 62,12 & 405,44 & & 57,92 & \\
\hline
\end{tabular}




\subsubsection{Dieta para el periodo de lesión}

La fecha del periodo de lesión no se puede concretar, puesto que éstas son imprevisible. Lo que se va a proponer durante este periodo, esencialmente, es tratar de disminuir la ingesta calórica para que no se produzca un aumento del peso corporal a causa de la inactividad. Mediante una correcta nutrición tanto de macronutrientes como micronutrientes vamos a tratar de acortar los tiempos de recuperación.

Tabla 28. Dieta en periodo de lesión: Primer día.

\begin{tabular}{|l|c|}
\hline \multicolumn{2}{|c|}{ DESAYUNO } \\
\hline Pan blanco de trigo sin sal & $60 \mathrm{~g}$ \\
\hline Leche de vaca desnatada & $250 \mathrm{~g}$ \\
\hline Cacao en polvo azucarado (2,5\% grasa) & $10 \mathrm{~g}$ \\
\hline Margarina & $10 \mathrm{~g}$ \\
\hline Agua & $200 \mathrm{~g}$ \\
\hline
\end{tabular}

\begin{tabular}{|l|l|}
\hline \multicolumn{2}{|c|}{ MEDIA MAÑANA } \\
\hline Plátano & $200 \mathrm{~g}$ \\
\hline Batido de cacao & $200 \mathrm{~g}$ \\
\hline Agua & $200 \mathrm{~g}$ \\
\hline
\end{tabular}

\begin{tabular}{|l|c|}
\hline \multicolumn{2}{|c|}{ MERIENDA } \\
\hline Nueces sin cáscara & $20 \mathrm{~g}$ \\
\hline Leche de vaca desnatada & $250 \mathrm{~g}$ \\
\hline Vainilla extracto & $5 \mathrm{~g}$ \\
\hline Galletas & $32 \mathrm{~g}$ \\
\hline
\end{tabular}

\begin{tabular}{|l|c|}
\hline \multicolumn{2}{|c|}{ COMIDA } \\
\hline Arroz blanco hervido & $140 \mathrm{~g}$ \\
\hline Tomate frito & $45 \mathrm{~g}$ \\
\hline Salchichas frescas & $20 \mathrm{~g}$ \\
\hline Zumo de naranja natural & $200 \mathrm{~g}$ \\
\hline Lechuga & $70 \mathrm{~g}$ \\
\hline Tomate & $30 \mathrm{~g}$ \\
\hline Agua & $600 \mathrm{~g}$ \\
\hline Huevo de gallina & $64 \mathrm{~g}$ \\
\hline Pan blanco de trigo sin sal & $60 \mathrm{~g}$ \\
\hline
\end{tabular}

\begin{tabular}{|l|c|}
\hline \multicolumn{2}{|c|}{ CENA } \\
\hline Pisto & 2 rac. $-456 \mathrm{~g}$ \\
\hline Pollo pechuga & $150 \mathrm{~g}$ \\
\hline Fresa fresón & $150 \mathrm{~g}$ \\
\hline Agua & $400 \mathrm{~g}$ \\
\hline Pan blanco de trigo sin sal & $60 \mathrm{~g}$ \\
\hline
\end{tabular}

Tabla 29. Dieta en periodo de lesión: Segundo día.

\begin{tabular}{|l|c|}
\hline \multicolumn{2}{|c|}{ DESAYUNO } \\
\hline Pan blanco de trigo sin sal & $60 \mathrm{~g}$ \\
\hline Leche de vaca desnatada & $250 \mathrm{~g}$ \\
\hline Cacao en polvo azucarado (2,5\% grasa) & $10 \mathrm{~g}$ \\
\hline Margarina & $10 \mathrm{~g}$ \\
\hline Agua & $200 \mathrm{~g}$ \\
\hline
\end{tabular}

\begin{tabular}{|l|c|}
\hline \multicolumn{2}{|c|}{ MEDIA MAÑANA } \\
\hline Batido de cacao & $200 \mathrm{~g}$ \\
\hline Agua & $200 \mathrm{~g}$ \\
\hline Cereales de desayuno & $60 \mathrm{~g}$ \\
\hline
\end{tabular}

\begin{tabular}{|l|c|}
\hline \multicolumn{2}{|c|}{ MERIENDA } \\
\hline Leche de vaca desnatada & $250 \mathrm{~g}$ \\
\hline Pan blanco tostado sin sal & $60 \mathrm{~g}$ \\
\hline Margarina & $8 \mathrm{~g}$ \\
\hline Cacao en polvo azucarado $(2,5 \%$ grasa $)$ & $10 \mathrm{~g}$ \\
\hline
\end{tabular}

\begin{tabular}{|l|c|}
\hline \multicolumn{2}{|c|}{ COMIDA } \\
\hline Zumo de naranja natural & $200 \mathrm{~g}$ \\
\hline Tomate & $30 \mathrm{~g}$ \\
\hline Agua & $600 \mathrm{~g}$ \\
\hline Pan blanco de trigo sin sal & $60 \mathrm{~g}$ \\
\hline Lechuga & $70 \mathrm{~g}$ \\
\hline Cebolla & $30 \mathrm{~g}$ \\
\hline Rape & $400 \mathrm{~g}$ \\
\hline Arroz blanco hervido & $250 \mathrm{~g}$ \\
\hline
\end{tabular}

\begin{tabular}{|l|c|}
\hline \multicolumn{2}{|c|}{ CENA } \\
\hline Fresa fresón & $150 \mathrm{~g}$ \\
\hline Agua & $400 \mathrm{~g}$ \\
\hline Pan blanco de trigo sin sal & $60 \mathrm{~g}$ \\
\hline Coliflor & $250 \mathrm{~g}$ \\
\hline Brécol & $200 \mathrm{~g}$ \\
\hline Huevo de gallina & $80 \mathrm{~g}$ \\
\hline Croquetas de carne & 1 rac. $-313 \mathrm{~g}$ \\
\hline
\end{tabular}


Tabla 30. Dieta en periodo de lesión: Tercer día.

\begin{tabular}{|l|c|}
\hline \multicolumn{2}{|c|}{ DESAYUNO } \\
\hline Pan blanco de trigo sin sal & $60 \mathrm{~g}$ \\
\hline Leche de vaca desnatada & $250 \mathrm{~g}$ \\
\hline Cacao en polvo azucarado $(2,5 \%$ grasa) & $10 \mathrm{~g}$ \\
\hline Margarina & $10 \mathrm{~g}$ \\
\hline Agua & $200 \mathrm{~g}$ \\
\hline
\end{tabular}

\begin{tabular}{|l|l|}
\hline \multicolumn{2}{|c|}{ MEDIA MAÑANA } \\
\hline Plátano & $200 \mathrm{~g}$ \\
\hline Batido de cacao & $200 \mathrm{~g}$ \\
\hline Agua & $200 \mathrm{~g}$ \\
\hline
\end{tabular}

\begin{tabular}{|l|c|}
\hline \multicolumn{2}{|c|}{ MERIENDA } \\
\hline Leche de vaca desnatada & $250 \mathrm{~g}$ \\
\hline Pan blanco tostado sin sal & $60 \mathrm{~g}$ \\
\hline Margarina & $8 \mathrm{~g}$ \\
\hline Miel & $20 \mathrm{~g}$ \\
\hline
\end{tabular}

\begin{tabular}{|l|c|}
\hline \multicolumn{2}{|c|}{ COMIDA } \\
\hline Zumo de naranja natural & $200 \mathrm{~g}$ \\
\hline Tomate & $30 \mathrm{~g}$ \\
\hline Agua & $600 \mathrm{~g}$ \\
\hline Pan blanco de trigo sin sal & $60 \mathrm{~g}$ \\
\hline Salmón & $200 \mathrm{~g}$ \\
\hline Patata & $170 \mathrm{~g}$ \\
\hline Lechuga & $70 \mathrm{~g}$ \\
\hline Cebolla & $30 \mathrm{~g}$ \\
\hline
\end{tabular}

\begin{tabular}{|l|c|}
\hline \multicolumn{2}{|c|}{ CENA } \\
\hline Fresa fresón & $150 \mathrm{~g}$ \\
\hline Agua & $400 \mathrm{~g}$ \\
\hline Pan blanco de trigo sin sal & $60 \mathrm{~g}$ \\
\hline Pasta al huevo hervida & $300 \mathrm{~g}$ \\
\hline Maiz desgranado en conserva & $30 \mathrm{~g}$ \\
\hline Atún & $30 \mathrm{~g}$ \\
\hline Boquerón & $100 \mathrm{~g}$ \\
\hline Natillas & $135 \mathrm{~g}$ \\
\hline
\end{tabular}

Tabla 31. Dieta en periodo de lesión: Cuarto día.

\begin{tabular}{|l|c|}
\hline \multicolumn{2}{|c|}{ DESAYUNO } \\
\hline Leche de vaca desnatada & $250 \mathrm{~g}$ \\
\hline Cacao en polvo azucarado (2,5\% grasa) & $10 \mathrm{~g}$ \\
\hline Pan blanco tostado sin sal & $60 \mathrm{~g}$ \\
\hline Margarina & $8 \mathrm{~g}$ \\
\hline Agua & $200 \mathrm{~g}$ \\
\hline
\end{tabular}

\begin{tabular}{|l|c|}
\hline \multicolumn{2}{|c|}{ MEDIA MAÑANA } \\
\hline Agua & $200 \mathrm{~g}$ \\
\hline Nueces sin cáscara & $20 \mathrm{~g}$ \\
\hline Batido de fresa & $200 \mathrm{~g}$ \\
\hline
\end{tabular}

\begin{tabular}{|l|c|}
\hline \multicolumn{2}{|c|}{ COMIDA } \\
\hline Agua & $600 \mathrm{~g}$ \\
\hline Judias verdes con jamón serrano & 1 rac.-311g \\
\hline Cordero chuleta & $80 \mathrm{~g}$ \\
\hline Pan blanco de trigo sin sal & $60 \mathrm{~g}$ \\
\hline Kiwi & $200 \mathrm{~g}$ \\
\hline
\end{tabular}

\begin{tabular}{|l|c|}
\hline \multicolumn{2}{|c|}{ MERIENDA } \\
\hline Agua & $200 \mathrm{~g}$ \\
\hline Leche de vaca desnatada & $250 \mathrm{~g}$ \\
\hline Cacao en polvo azucarado (2,5\% grasa) & $10 \mathrm{~g}$ \\
\hline Pan blanco tostado sin sal & $60 \mathrm{~g}$ \\
\hline Aceite de oliva & $10 \mathrm{~g}$ \\
\hline
\end{tabular}

\begin{tabular}{|l|c|}
\hline \multicolumn{2}{|c|}{ CENA } \\
\hline Agua & $400 \mathrm{~g}$ \\
\hline Pan blanco de trigo sin sal & $50 \mathrm{~g}$ \\
\hline Lechuga & $100 \mathrm{~g}$ \\
\hline Tomate & $50 \mathrm{~g}$ \\
\hline Cebolla & $20 \mathrm{~g}$ \\
\hline Huevo de gallina & $16 \mathrm{~g}$ \\
\hline Arroz tres delicias & 2 rac. $-390 \mathrm{~g}$ \\
\hline Plátano & $160 \mathrm{~g}$ \\
\hline
\end{tabular}


Tabla 32. Dieta en periodo de lesión: Quinto día.

\begin{tabular}{|c|c|}
\hline \multicolumn{2}{|l|}{ DESAYUNO } \\
\hline Leche de vaca desnatada & $250 \mathrm{~g}$ \\
\hline Cacao en polvo azucarado ( $2,5 \%$ grasa) & $10 \mathrm{~g}$ \\
\hline Pan blanco tostado sin sal & $60 \mathrm{~g}$ \\
\hline Agua & $200 \mathrm{~g}$ \\
\hline Margarina & $10 \mathrm{~g}$ \\
\hline \multicolumn{2}{|l|}{ MEDIA MAÑANA } \\
\hline Agua & $200 \mathrm{~g}$ \\
\hline Plátano & $200 \mathrm{~g}$ \\
\hline
\end{tabular}

\begin{tabular}{|l|c|}
\hline \multicolumn{2}{|c|}{ MERIENDA } \\
\hline Agua & $200 \mathrm{~g}$ \\
\hline Leche de vaca desnatada & $250 \mathrm{~g}$ \\
\hline Cacao en polvo azucarado $(2,5 \%$ grasa) & $10 \mathrm{~g}$ \\
\hline Pan blanco tostado sin sal & $60 \mathrm{~g}$ \\
\hline Margarina & $10 \mathrm{~g}$ \\
\hline
\end{tabular}

\begin{tabular}{|l|c|}
\hline \multicolumn{2}{|c|}{ COMIDA } \\
\hline Agua & $600 \mathrm{~g}$ \\
\hline Pan blanco de trigo sin sal & $60 \mathrm{~g}$ \\
\hline Zumo de naranja natural & $200 \mathrm{~g}$ \\
\hline Boquerones fritos & 0.6 rac. $-174.6 \mathrm{~g}$ \\
\hline Potaje de garbanzos & 1.5 rac.-232.5g \\
\hline
\end{tabular}

\begin{tabular}{|l|c|}
\hline \multicolumn{2}{|c|}{ MERIENDA } \\
\hline Agua & $200 \mathrm{~g}$ \\
\hline Leche de vaca desnatada & $250 \mathrm{~g}$ \\
\hline Cacao en polvo azucarado (2,5\% grasa) & $10 \mathrm{~g}$ \\
\hline Pan blanco tostado sin sal & $60 \mathrm{~g}$ \\
\hline Margarina & $10 \mathrm{~g}$ \\
\hline
\end{tabular}

\begin{tabular}{|l|c|}
\hline \multicolumn{2}{|c|}{ CENA } \\
\hline Agua & $400 \mathrm{~g}$ \\
\hline Pan blanco de trigo sin sal & $50 \mathrm{~g}$ \\
\hline Lechuga & $100 \mathrm{~g}$ \\
\hline Tomate & $50 \mathrm{~g}$ \\
\hline Cebolla & $20 \mathrm{~g}$ \\
\hline Pera & $190 \mathrm{~g}$ \\
\hline Almejas & $150 \mathrm{~g}$ \\
\hline Ajo & $5 \mathrm{~g}$ \\
\hline Ensaladilla rusa & $1 \mathrm{rac} .-251 \mathrm{~g}$ \\
\hline Aceite de oliva & $5 \mathrm{~g}$ \\
\hline
\end{tabular}

Tabla 33. Dieta en periodo de lesión: Sexto día.

\begin{tabular}{|l|c|}
\hline \multicolumn{2}{|c|}{ DESAYUNO } \\
\hline Leche de vaca desnatada & $250 \mathrm{~g}$ \\
\hline Cacao en polvo azucarado (2,5\% grasa) & $10 \mathrm{~g}$ \\
\hline Pan blanco tostado sin sal & $60 \mathrm{~g}$ \\
\hline Agua & $200 \mathrm{~g}$ \\
\hline Aceite de oliva & $10 \mathrm{~g}$ \\
\hline Tomate & $15 \mathrm{~g}$ \\
\hline Jamón serrano & $30 \mathrm{~g}$ \\
\hline
\end{tabular}

\begin{tabular}{|l|c|}
\hline \multicolumn{2}{|c|}{ MERIENDA } \\
\hline Agua & $200 \mathrm{~g}$ \\
\hline Leche de vaca desnatada & $250 \mathrm{~g}$ \\
\hline Cacao en polvo azucarado (2,5\% grasa) & $10 \mathrm{~g}$ \\
\hline Cereales de desayuno & $60 \mathrm{~g}$ \\
\hline
\end{tabular}

\begin{tabular}{|l|c|}
\hline \multicolumn{2}{|c|}{ COMIDA } \\
\hline Agua & $600 \mathrm{~g}$ \\
\hline Pan blanco de trigo sin sal & $60 \mathrm{~g}$ \\
\hline Zumo de naranja natural & $200 \mathrm{~g}$ \\
\hline Pescadilla cocida & 1 rac. $225 \mathrm{~g}$ \\
\hline Arroz blanco hervido & $220 \mathrm{~g}$ \\
\hline
\end{tabular}

\begin{tabular}{|l|c|}
\hline \multicolumn{2}{|c|}{ MERIENDA } \\
\hline Agua & $200 \mathrm{~g}$ \\
\hline Leche de vaca desnatada & $250 \mathrm{~g}$ \\
\hline Cacao en polvo azucarado (2,5\% grasa) & $10 \mathrm{~g}$ \\
\hline Cereales de desayuno & $60 \mathrm{~g}$ \\
\hline
\end{tabular}

\begin{tabular}{|l|c|}
\hline \multicolumn{2}{|c|}{ CENA } \\
\hline Agua & $400 \mathrm{~g}$ \\
\hline Pan blanco de trigo sin sal & $50 \mathrm{~g}$ \\
\hline Lechuga & $100 \mathrm{~g}$ \\
\hline Tomate & $50 \mathrm{~g}$ \\
\hline Cebolla & $20 \mathrm{~g}$ \\
\hline Pera & $190 \mathrm{~g}$ \\
\hline Ajo & $5 \mathrm{~g}$ \\
\hline Lasaña (pasta) & $76 \mathrm{~g}$ \\
\hline Huevo relleno (1) & 1 rac.-138g \\
\hline Helado cremoso & $115 \mathrm{~g}$ \\
\hline
\end{tabular}


Tabla 34. Dieta en periodo de lesión: Séptimo día.

\begin{tabular}{|l|c|}
\hline \multicolumn{2}{|c|}{ DESAYUNO } \\
\hline Leche de vaca desnatada & $250 \mathrm{~g}$ \\
\hline Agua & $200 \mathrm{~g}$ \\
\hline Churros & $100 \mathrm{~g}$ \\
\hline Cacao en polvo azucarado (2,5\% grasa) & $10 \mathrm{~g}$ \\
\hline
\end{tabular}

\begin{tabular}{|l|c|}
\hline \multicolumn{2}{|c|}{ COMIDA } \\
\hline Agua & $600 \mathrm{~g}$ \\
\hline Pan blanco de trigo sin sal & $60 \mathrm{~g}$ \\
\hline Pisto manchego & 1 rac. $-393 \mathrm{~g}$ \\
\hline Pollo & $200 \mathrm{~g}$ \\
\hline Pera en almibar & $150 \mathrm{~g}$ \\
\hline
\end{tabular}

\begin{tabular}{|l|c|}
\hline \multicolumn{2}{|c|}{ MERIENDA } \\
\hline Agua & $200 \mathrm{~g}$ \\
\hline Leche de vaca desnatada & $250 \mathrm{~g}$ \\
\hline Cacao en polvo azucarado (2,5\% grasa) & $10 \mathrm{~g}$ \\
\hline Cereales de desayuno & $60 \mathrm{~g}$ \\
\hline Galletas & $32 \mathrm{~g}$ \\
\hline
\end{tabular}

\begin{tabular}{|l|c|}
\hline \multicolumn{2}{|c|}{ CENA } \\
\hline Agua & $400 \mathrm{~g}$ \\
\hline Pan blanco de trigo sin sal & $50 \mathrm{~g}$ \\
\hline Lechuga & $100 \mathrm{~g}$ \\
\hline Tomate & $50 \mathrm{~g}$ \\
\hline Cebolla & $20 \mathrm{~g}$ \\
\hline Ajo & $5 \mathrm{~g}$ \\
\hline Plátano & $200 \mathrm{~g}$ \\
\hline Puré de patatas & 1 rac. $-315 \mathrm{~g}$ \\
\hline Calamares a la romana & 1 rac. $-206 \mathrm{~g}$ \\
\hline
\end{tabular}


Tabla 35. Resumen semanal dieta en periodo de lesión

\begin{tabular}{|c|c|c|c|c|c|c|c|c|c|c|c|}
\hline & Día 1 & Día 2 & Día 3 & Día 4 & Día 5 & Día 6 & Día 7 & Total & Kcal & Media & $\%$ Kcal \\
\hline \multicolumn{12}{|l|}{ GENERAL } \\
\hline Agua (g) & $3.229,24$ & $3.407,43$ & $3.222,23$ & $3.033,05$ & $2.989,70$ & $2.836,27$ & $3.034,88$ & $21.752,80$ & & $3.107,54$ & \\
\hline Energía (kcal) & $2.881,02$ & $2.833,07$ & $2.605,61$ & $2.828,27$ & $2.705,37$ & $2.535,32$ & $2.632,84$ & $19.021,50$ & $19.021,50$ & $2.717,36$ & $100 \%$ \\
\hline Energía (kJ) & $12.056,65$ & $11.853,19$ & $10.898,47$ & $11.831,71$ & $11.313,29$ & $10.602,02$ & $11.018,13$ & $79.573,46$ & & $11.367,64$ & \\
\hline Proteínas (g) & 138,47 & 143,17 & 118,42 & 116,89 & 105,74 & 102,32 & 111,1 & 836,11 & $3.344,44$ & 119,44 & $17,59 \%$ \\
\hline Grasa total $(\mathrm{g})$ & 91,32 & 73,34 & 63,18 & 91,42 & 107,96 & 68,69 & 88,35 & 584,26 & $5.258,34$ & 83,47 & $27,65 \%$ \\
\hline Hidratos de carbono totales (g) & 376,7 & 399,69 & 390,73 & 384,53 & 327,47 & 376,33 & 348,06 & $2.603,51$ & $10.414,04$ & 371,93 & $54,76 \%$ \\
\hline Azúcares $(\mathrm{g})$ & 136,27 & 118,75 & 150,19 & 112,22 & 116,77 & 120,85 & 119,6 & 874,65 & & 124,95 & \\
\hline Almidón (g) & 240,38 & 280,94 & 240,51 & 272,37 & 210,79 & 255,53 & 228,66 & $1.729,18$ & & 247,03 & \\
\hline Fibra dietética (g) & 22,15 & 24 & 23,62 & 23,81 & 39,38 & 17,89 & 24,86 & 175,71 & & 25,10 & \\
\hline Grasa saturada (AGS) (g) & 22,78 & 24,46 & 19,31 & 20,62 & 19,37 & 20,7 & 18,38 & 145,62 & $1.310,58$ & 20,80 & $7,60 \%$ \\
\hline Grasa monoinsaturada (AGM) (g) & 39,2 & 26,42 & 19,07 & 42,49 & 59,02 & 32,93 & 44,57 & 263,70 & $2.373,30$ & 37,67 & $13,76 \%$ \\
\hline Grasa poliinsaturada (AGP) (g) & 22,14 & 13,43 & 14,3 & 20,58 & 22,16 & 8,51 & 19,41 & 120,53 & $1.084,77$ & 17,22 & $6,29 \%$ \\
\hline Colesterol (mg) & 507,02 & 542,54 & 228,52 & 441,71 & 334,71 & 385,37 & 542,91 & $2.982,78$ & & 426,11 & \\
\hline \multicolumn{12}{|l|}{ MINERALES } \\
\hline Calcio (mg) & $1.238,31$ & $1.494,29$ & $1.391,74$ & $1.311,56$ & $1.174,44$ & $1.146,34$ & $1.067,63$ & $8.824,31$ & & $1.260,62$ & \\
\hline Hierro (mg) & 16,25 & 24,25 & 13,46 & 15,72 & 24,62 & 16,56 & 19,43 & 130,29 & & 18,61 & \\
\hline Yodo $(\mu \mathrm{g})$ & 538,5 & 659,53 & 533,15 & 592,17 & 591,84 & 533,98 & 655,12 & $4.104,29$ & & 586,33 & \\
\hline Magnesio (mg) & 444,13 & 408,27 & 431,13 & 398,02 & 497,99 & 298,61 & 399,86 & $2.878,01$ & & 411,14 & \\
\hline Cinc (mg) & 11,9 & 15,94 & 11,45 & 11,64 & 8,39 & 10,78 & 10,14 & 80,24 & & 11,46 & \\
\hline Sodio (mg) & $3.591,98$ & $2.948,27$ & $1.073,31$ & $3.020,32$ & $3.609,52$ & $3.067,81$ & $3.671,15$ & $20.982,36$ & & $2.997,48$ & \\
\hline Potasio (mg) & $5.094,77$ & $4.890,80$ & $4.714,68$ & $4.592,90$ & $4.733,31$ & $3.137,68$ & $5.247,74$ & $32.411,88$ & & $4.630,27$ & \\
\hline Fósforo (mg) & $1.965,98$ & $2.676,33$ & $2.036,21$ & $1.891,96$ & $1.845,09$ & $1.701,44$ & $1.856,30$ & $13.973,31$ & & $1.996,19$ & \\
\hline Selenio $(\mu \mathrm{g})$ & 0,00 & 0,00 & 23,12 & 30,69 & 2,89 & 0,00 & 0,00 & 56,70 & & 8,10 & \\
\hline \multicolumn{12}{|l|}{ VITAMINAS } \\
\hline Tiamina o Vitamina B1 (mg) & 1,57 & 2,42 & 1,61 & 1,84 & 1,67 & 2,37 & 2,04 & 13,52 & & 1,93 & \\
\hline Riboflavina o Vitamina B2 (mg) & 2,54 & 3,69 & 2,54 & 2,38 & 2,15 & 2,71 & 2,76 & 18,77 & & 2,68 & \\
\hline Eq. niacina (mg) & 65,47 & 53,49 & 44,56 & 40,02 & 30,93 & 40,46 & 47,32 & 322,25 & & 46,04 & \\
\hline Vitamina B6 (mg) & 3,6 & 3,03 & 3,87 & 2,64 & 3,45 & 2,46 & 3,8 & 22,85 & & 3,26 & \\
\hline Ácido fólico $(\mu \mathrm{g})$ & 389,28 & 637,1 & 311,2 & 291,06 & 499,19 & 376,39 & 332,6 & $2.836,82$ & & 405,26 & \\
\hline Vitamina B12 ( $\mu \mathrm{g})$ & 3,51 & 10,8 & 12,49 & 3,83 & 6,69 & 5,13 & 4,44 & 46,89 & & 6,70 & \\
\hline Vitamina C (mg) & 329,72 & 439,32 & 235,28 & 193,09 & 182,77 & 126,9 & 219,17 & $1.726,25$ & & 246,61 & \\
\hline Vitamina A: Eq. retinol $(\mu \mathrm{g})$ & 845,99 & 706,32 & 470,81 & 359,44 & $1.223,26$ & 301,77 & 670,84 & $4.578,43$ & & 654,06 & \\
\hline Retinol $(\mu \mathrm{g})$ & 252,21 & 511,51 & 353,14 & 230,09 & 365,79 & 179,88 & 147,58 & $2.040,20$ & & 291,46 & \\
\hline Carotenos $(\mu \mathrm{g})$ & $3.309,42$ & 946,15 & 577,69 & 818,26 & $5.643,20$ & 682,24 & $3.090,85$ & $15.067,81$ & & $2.152,54$ & \\
\hline Vitamina D $(\mu \mathrm{g})$ & 1,61 & 4,9 & 26,11 & 1,07 & 9,22 & 3,75 & 2,77 & 49,43 & & 7,06 & \\
\hline Vitamina E (mg) & 6,6 & 6,49 & 3,39 & 5,21 & 11,12 & 4,77 & 9,49 & 47,07 & & 6,72 & \\
\hline \multicolumn{12}{|l|}{ ÁCIDOS GRASOS } \\
\hline Grasa total (g) & 91,32 & 73,34 & 63,18 & 91,42 & 107,96 & 68,69 & 88,35 & 584,26 & & 83,47 & \\
\hline Grasa saturada (AGS) (g) & 22,78 & 24,46 & 19,31 & 20,62 & 19,37 & 20,7 & 18,38 & 145,62 & & 20,80 & \\
\hline Grasa monoinsaturada (AGM) (g) & 39,2 & 26,42 & 19,07 & 42,49 & 59,02 & 32,93 & 44,57 & 263,70 & & 37,67 & \\
\hline Grasa poliinsaturada (AGP) (g) & 22,14 & 13,43 & 14,3 & 20,58 & 22,16 & 8,51 & 19,41 & 120,53 & & 17,22 & \\
\hline Colesterol (mg) & 507,02 & 542,54 & 228,52 & 441,71 & 334,71 & 385,37 & 542,91 & $2.982,78$ & & 426,11 & \\
\hline C12:0 (g) - Ac. láurico - Ac. dodecanoico & 0,47 & 0,8 & 0,45 & 0,28 & 0,48 & 4,49 & 0,28 & 7,25 & & 1,04 & \\
\hline C14:0 (g) - Ac. mirístico - Ac. tetradecanoico & 1,23 & 2,18 & 2,47 & 1,07 & 0,66 & 1,86 & 0,77 & 10,24 & & 1,46 & \\
\hline C16:0 (g) - Ac. palmítico - Ac. hexadecanoico & 13,91 & 12,73 & 9,31 & 13,1 & 12,99 & 8,77 & 11,64 & 82,45 & & 11,78 & \\
\hline C18:0 (g) - Ac. esteárico - Ac. octadecanoico & 5,21 & 5,45 & 3,95 & 4,46 & 4,05 & 3,31 & 4,23 & 30,66 & & 4,38 & \\
\hline C18:1 (g) - Ac. oleico - Ac. octadecenoico & 37,21 & 24,4 & 11,61 & 40,72 & 57,13 & 31,51 & 42,77 & 245,35 & & 35,05 & \\
\hline C18:2 (g) - Ac. linoleico - Ac. octadecadienoico & 19,47 & 11,15 & 8,45 & 17,74 & 18,49 & 7,39 & 17,42 & 100,11 & & 14,30 & \\
\hline C18:3 (g) - Ac. a-linolénico - Ac. octadecatrienoico & 2,11 & 0,66 & 0,8 & 2,12 & 1,11 & 0,43 & 0,88 & 8,11 & & 1,16 & \\
\hline C20:4 (g) - Ac. araquidónico - Ac. eicosatetraenoico & 0,07 & 0,04 & 0,1 & 0,09 & 0,03 & 0,02 & 0,06 & 0,41 & & 0,06 & \\
\hline C20:5 (g) - EPA - Ac. eicosapentaenoico & 0 & 0 & 1,31 & 0,07 & 0,77 & 0 & 0,21 & 2,36 & & 0,34 & \\
\hline C22:6 (g) - DHA - Ac. docosahexaenoico & 0 & 0 & 2,52 & 0,05 & 1,34 & 0,13 & 0,48 & 4,52 & & 0,65 & \\
\hline Ácidos grasos cis $(\mathrm{g})$ & 46,06 & 31,8 & 20,35 & 47,94 & 38,16 & 23,38 & 44,9 & 252,59 & & 36,08 & \\
\hline
\end{tabular}




\subsubsection{Dieta para el periodo de descanso}

El periodo de descanso se llevará a cabo en los meses de junio, julio y agosto. En estos meses cabe destacar el clima caluroso del sur de España, por lo que habrá que cuidar con detalle la hidratación. Como la actividad física no es tan continúa y exigente, el gasto calórico bajará, por lo que se debe adaptar la ingesta a las nuevas necesidades. Pese a ello, durante este periodo se ha planteado como objetivo la ganancia de peso, sobre todo de masa muscular por lo que será necesario un entrenamiento de resistido complementario. Se aumentó las cantidades de proteínas respecto a los otros macronutrientes en comparación con otros periodos, pues se buscaba una mayor regeneración del tejido muscular, sin importarnos el rendimiento.

Tabla 36. Dieta en periodo de descanso: Primer día.

\begin{tabular}{|l|c|}
\hline \multicolumn{2}{|c|}{ DESAYUNO } \\
\hline Agua & $300 \mathrm{~g}$ \\
\hline Leche de vaca desnatada & $250 \mathrm{~g}$ \\
\hline Cereales de desayuno & $30 \mathrm{~g}$ \\
\hline Pan blanco tostado sin sal & $60 \mathrm{~g}$ \\
\hline Margarina & $10 \mathrm{~g}$ \\
\hline Cacao en polvo azucarado $(2,5 \%$ grasa $)$ & $10 \mathrm{~g}$ \\
\hline
\end{tabular}

\begin{tabular}{|l|c|}
\hline \multicolumn{2}{|c|}{ COMIDA } \\
\hline Pan blanco de trigo sin sal & $65 \mathrm{~g}$ \\
\hline Agua & $600 \mathrm{~g}$ \\
\hline Cerdo paletilla & $150 \mathrm{~g}$ \\
\hline Cerdo carne magra & $150 \mathrm{~g}$ \\
\hline Patatas fritas caseras & 1 rac. $-166 \mathrm{~g}$ \\
\hline Lechuga & $100 \mathrm{~g}$ \\
\hline Tomate & $50 \mathrm{~g}$ \\
\hline Cebolla & $30 \mathrm{~g}$ \\
\hline Maiz desgranado en conserva & $35 \mathrm{~g}$ \\
\hline Sandia & $300 \mathrm{~g}$ \\
\hline
\end{tabular}

\begin{tabular}{|l|c|}
\hline \multicolumn{2}{|c|}{ MERIENDA } \\
\hline Batido de vainilla & $200 \mathrm{~g}$ \\
\hline Cereales de desayuno & $50 \mathrm{~g}$ \\
\hline Agua & $200 \mathrm{~g}$ \\
\hline
\end{tabular}

\begin{tabular}{|l|c|}
\hline \multicolumn{2}{|c|}{ CENA } \\
\hline Pan blanco de trigo sin sal & $50 \mathrm{~g}$ \\
\hline Agua & $400 \mathrm{~g}$ \\
\hline Melón & $300 \mathrm{~g}$ \\
\hline Pasta al huevo & $140 \mathrm{~g}$ \\
\hline
\end{tabular}

Tabla 37. Dieta en periodo de descanso: Segundo día.

\begin{tabular}{|l|c|}
\hline \multicolumn{2}{|c|}{ DESAYUNO } \\
\hline Agua & $300 \mathrm{~g}$ \\
\hline Leche de vaca desnatada & $250 \mathrm{~g}$ \\
\hline Pan blanco tostado sin sal & $60 \mathrm{~g}$ \\
\hline Margarina & $10 \mathrm{~g}$ \\
\hline Cacao en polvo azucarado (2,5\% grasa) & $10 \mathrm{~g}$ \\
\hline
\end{tabular}

\begin{tabular}{|l|c|}
\hline \multicolumn{2}{|c|}{ MEDIA MAÑANA } \\
\hline Pistacho con cáscara & $50 \mathrm{~g}$ \\
\hline
\end{tabular}

\begin{tabular}{|l|c|}
\hline \multicolumn{2}{|c|}{ MERIENDA } \\
\hline Agua & $200 \mathrm{~g}$ \\
\hline Leche de vaca desnatada & $250 \mathrm{~g}$ \\
\hline Miel & $20 \mathrm{~g}$ \\
\hline Galletas tipo Maria & $36 \mathrm{~g}$ \\
\hline
\end{tabular}

\begin{tabular}{|l|c|}
\hline \multicolumn{2}{|c|}{ COMIDA } \\
\hline Pan blanco de trigo sin sal & $65 \mathrm{~g}$ \\
\hline Agua & $600 \mathrm{~g}$ \\
\hline Lechuga & $100 \mathrm{~g}$ \\
\hline Tomate & $50 \mathrm{~g}$ \\
\hline Cebolla & $30 \mathrm{~g}$ \\
\hline Maiz desgranado en conserva & $35 \mathrm{~g}$ \\
\hline Sandia & $300 \mathrm{~g}$ \\
\hline Macarrones gratinados & 1 rac. $-143 \mathrm{~g}$ \\
\hline Huevo de gallina & $64 \mathrm{~g}$ \\
\hline
\end{tabular}

\begin{tabular}{|l|c|}
\hline \multicolumn{2}{|c|}{ CENA } \\
\hline Pan blanco de trigo sin sal & $50 \mathrm{~g}$ \\
\hline Agua & $400 \mathrm{~g}$ \\
\hline Melón & $300 \mathrm{~g}$ \\
\hline Bacalao al ajo arriero & 1 rac. $-186 \mathrm{~g}$ \\
\hline Pollo empanado congelado & $180 \mathrm{~g}$ \\
\hline Patatas asadas & 1rac.-218g \\
\hline
\end{tabular}


Tabla 38. Dieta en periodo de descanso: Tercer día.

\begin{tabular}{|l|c|}
\hline \multicolumn{2}{|c|}{ DESAYUNO } \\
\hline Agua & $200 \mathrm{~g}$ \\
\hline Leche de vaca desnatada & $250 \mathrm{~g}$ \\
\hline Cacao en polvo azucarado $(2,5 \%$ grasa $)$ & $10 \mathrm{~g}$ \\
\hline Pan blanco tostado sin sal & $60 \mathrm{~g}$ \\
\hline Margarina & $10 \mathrm{~g}$ \\
\hline Galletas tipo Maria & $30 \mathrm{~g}$ \\
\hline
\end{tabular}

\begin{tabular}{|l|l|}
\hline \multicolumn{2}{|c|}{ MEDIA MAÑANA } \\
\hline Plátano & $200 \mathrm{~g}$ \\
\hline
\end{tabular}

\begin{tabular}{|l|c|}
\hline \multicolumn{2}{|c|}{ COMIDA } \\
\hline Raya & $200 \mathrm{~g}$ \\
\hline Arroz blanco hervido & $220 \mathrm{~g}$ \\
\hline Sandia & $300 \mathrm{~g}$ \\
\hline Agua & $600 \mathrm{~g}$ \\
\hline Lechuga & $100 \mathrm{~g}$ \\
\hline Tomate & $30 \mathrm{~g}$ \\
\hline Cebolla & $20 \mathrm{~g}$ \\
\hline Huevo de gallina & $30 \mathrm{~g}$ \\
\hline Aceitunas con hueso & $12 \mathrm{~g}$ \\
\hline Rape & $200 \mathrm{~g}$ \\
\hline
\end{tabular}

\begin{tabular}{|l|c|}
\hline \multicolumn{2}{|c|}{ MERIENDA } \\
\hline Cacao en polvo azucarado $(2,5 \%$ grasa $)$ & $10 \mathrm{~g}$ \\
\hline Leche de vaca desnatada & $250 \mathrm{~g}$ \\
\hline Agua & $200 \mathrm{~g}$ \\
\hline Pan blanco tostado & $60 \mathrm{~g}$ \\
\hline Margarina & $10 \mathrm{~g}$ \\
\hline Cereales de desayuno & $45 \mathrm{~g}$ \\
\hline
\end{tabular}

Cereales de desayuno
\begin{tabular}{|l|c|}
\hline \multicolumn{2}{|c|}{ CENA } \\
\hline \multicolumn{2}{|c|}{$45 \mathrm{~g}$} \\
\hline Langostino & $150 \mathrm{~g}$ \\
\hline Judias verdes con patatas & 1 rac. $-363 \mathrm{~g}$ \\
\hline Melón & $300 \mathrm{~g}$ \\
\hline Croquetas de pollo & 1 rac. $-214 \mathrm{~g}$ \\
\hline Helado cremoso & $115 \mathrm{~g}$ \\
\hline
\end{tabular}

Tabla 39. Dieta en periodo de descanso: Cuarto día.

\begin{tabular}{|l|c|}
\hline \multicolumn{2}{|c|}{ DESAYUNO } \\
\hline Agua & $400 \mathrm{~g}$ \\
\hline Leche de vaca desnatada & $250 \mathrm{~g}$ \\
\hline Cacao en polvo azucarado $(2,5 \%$ grasa $)$ & $10 \mathrm{~g}$ \\
\hline Pan blanco tostado sin sal & $60 \mathrm{~g}$ \\
\hline Margarina & $10 \mathrm{~g}$ \\
\hline Galletas tipo Maria & $30 \mathrm{~g}$ \\
\hline
\end{tabular}

\begin{tabular}{|l|c|}
\hline \multicolumn{2}{|c|}{ COMIDA } \\
\hline Sandia & $300 \mathrm{~g}$ \\
\hline Agua & $600 \mathrm{~g}$ \\
\hline Lechuga & $100 \mathrm{~g}$ \\
\hline Tomate & $30 \mathrm{~g}$ \\
\hline Cebolla & $20 \mathrm{~g}$ \\
\hline Huevo de gallina & $30 \mathrm{~g}$ \\
\hline Aceitunas con hueso & $12 \mathrm{~g}$ \\
\hline Lentejas guisadas & 1 rac. $-223 \mathrm{~g}$ \\
\hline Ternera carne magra & $45 \mathrm{~g}$ \\
\hline Tocino & $12 \mathrm{~g}$ \\
\hline Chorizo (21\% grasa) & $20 \mathrm{~g}$ \\
\hline
\end{tabular}

\begin{tabular}{|l|c|}
\hline \multicolumn{2}{|c|}{ MERIENDA } \\
\hline Cacao en polvo azucarado (2,5\% grasa) & $10 \mathrm{~g}$ \\
\hline Leche de vaca desnatada & $250 \mathrm{~g}$ \\
\hline Agua & $400 \mathrm{~g}$ \\
\hline Pan blanco tostado & $60 \mathrm{~g}$ \\
\hline Margarina & $10 \mathrm{~g}$ \\
\hline Cereales de desayuno & $45 \mathrm{~g}$ \\
\hline
\end{tabular}

\begin{tabular}{|l|c|}
\hline \multicolumn{2}{|c|}{ CENA } \\
\hline Melón & $300 \mathrm{~g}$ \\
\hline Tortilla francesa (1 huevo) & 1 rac. $-76 \mathrm{~g}$ \\
\hline Sopa de pasta & 3 rac. $-99 \mathrm{~g}$ \\
\hline Pollo & $200 \mathrm{~g}$ \\
\hline Agua & $200 \mathrm{~g}$ \\
\hline
\end{tabular}


Tabla 40. Dieta en periodo de descanso: Quinto día.

\begin{tabular}{|l|c|}
\hline \multicolumn{2}{|c|}{ DESAYUNO } \\
\hline Agua & $400 \mathrm{~g}$ \\
\hline Leche de vaca desnatada & $250 \mathrm{~g}$ \\
\hline Cacao en polvo azucarado (2,5\% grasa) & $10 \mathrm{~g}$ \\
\hline Pan blanco tostado sin sal & $60 \mathrm{~g}$ \\
\hline Margarina & $10 \mathrm{~g}$ \\
\hline
\end{tabular}

\begin{tabular}{|l|c|}
\hline \multicolumn{2}{|c|}{ COMIDA } \\
\hline Sandia & $300 \mathrm{~g}$ \\
\hline Agua & $600 \mathrm{~g}$ \\
\hline Lechuga & $100 \mathrm{~g}$ \\
\hline Tomate & $30 \mathrm{~g}$ \\
\hline Cebolla & $20 \mathrm{~g}$ \\
\hline Patatas guisadas con carne & 1.5 rac. $-573 \mathrm{~g}$ \\
\hline Pan blanco de trigo sin sal & $60 \mathrm{~g}$ \\
\hline
\end{tabular}

\begin{tabular}{|l|c|}
\hline \multicolumn{2}{|c|}{ MERIENDA } \\
\hline Cacao en polvo azucarado (2,5\% grasa) & $10 \mathrm{~g}$ \\
\hline Leche de vaca desnatada & $250 \mathrm{~g}$ \\
\hline Agua & $400 \mathrm{~g}$ \\
\hline Pan blanco tostado & $60 \mathrm{~g}$ \\
\hline Margarina & $10 \mathrm{~g}$ \\
\hline
\end{tabular}

\begin{tabular}{|l|c|}
\hline \multicolumn{2}{|c|}{ CENA } \\
\hline Melón & $300 \mathrm{~g}$ \\
\hline Agua & $200 \mathrm{~g}$ \\
\hline Atún & $160 \mathrm{~g}$ \\
\hline Pan blanco tostado & $90 \mathrm{~g}$ \\
\hline Lasaña (pasta) & $76 \mathrm{~g}$ \\
\hline
\end{tabular}

Tabla 41. Dieta en periodo de descanso: Sexto día.

\begin{tabular}{|l|c|}
\hline \multicolumn{2}{|c|}{ DESAYUNO } \\
\hline Agua & $400 \mathrm{~g}$ \\
\hline Leche de vaca desnatada & $250 \mathrm{~g}$ \\
\hline Cacao en polvo azucarado $(2,5 \%$ grasa) & $10 \mathrm{~g}$ \\
\hline Pan blanco tostado sin sal & $60 \mathrm{~g}$ \\
\hline Margarina & $10 \mathrm{~g}$ \\
\hline
\end{tabular}

\begin{tabular}{|l|c|}
\hline \multicolumn{2}{|c|}{ MEDIA MAÑANA } \\
\hline Batata & $150 \mathrm{~g}$ \\
\hline
\end{tabular}

\begin{tabular}{|l|c|}
\hline \multicolumn{2}{|c|}{ MERIENDA } \\
\hline Cacao en polvo azucarado (2,5\% grasa) & $10 \mathrm{~g}$ \\
\hline Leche de vaca desnatada & $250 \mathrm{~g}$ \\
\hline Agua & $400 \mathrm{~g}$ \\
\hline Galletas & $40 \mathrm{~g}$ \\
\hline Cereales de desayuno & $39 \mathrm{~g}$ \\
\hline
\end{tabular}

\begin{tabular}{|l|c|}
\hline \multicolumn{2}{|c|}{ COMIDA } \\
\hline Sandia & $300 \mathrm{~g}$ \\
\hline Agua & $600 \mathrm{~g}$ \\
\hline Pan blanco de trigo sin sal & $60 \mathrm{~g}$ \\
\hline Ensalada de lechuga tomate y cebolla & $250 \mathrm{~g}$ \\
\hline Langostino & $150 \mathrm{~g}$ \\
\hline Arroz blanco hervido & $300 \mathrm{~g}$ \\
\hline Gamba & $75 \mathrm{~g}$ \\
\hline
\end{tabular}

\begin{tabular}{|l|c|}
\hline \multicolumn{2}{|c|}{ CENA } \\
\hline Agua & $200 \mathrm{~g}$ \\
\hline Pan blanco de trigo sin sal & $60 \mathrm{~g}$ \\
\hline Uvas blancas & $160 \mathrm{~g}$ \\
\hline Queso Parmesano & $30 \mathrm{~g}$ \\
\hline Pizza cuatro estaciones & 1 rac.- $337 \mathrm{~g}$ \\
\hline Huevo relleno (1) & 1rac.-138g \\
\hline
\end{tabular}


Tabla 42. Dieta en periodo de descanso: Séptimo día.

\begin{tabular}{|l|c|}
\hline \multicolumn{2}{|c|}{ DESAYUNO } \\
\hline Agua & $400 \mathrm{~g}$ \\
\hline Leche de vaca desnatada & $250 \mathrm{~g}$ \\
\hline Cacao en polvo azucarado $(2,5 \%$ grasa) & $10 \mathrm{~g}$ \\
\hline Pan blanco tostado sin sal & $60 \mathrm{~g}$ \\
\hline Margarina & $10 \mathrm{~g}$ \\
\hline
\end{tabular}

\begin{tabular}{|l|c|}
\hline \multicolumn{2}{|c|}{ MEDIA MANANA } \\
\hline Pera & $190 \mathrm{~g}$ \\
\hline Agua & $200 \mathrm{~g}$ \\
\hline Queso Parmesano & $30 \mathrm{~g}$ \\
\hline
\end{tabular}

\begin{tabular}{|l|r|}
\hline \multicolumn{2}{|c|}{ MERIENDA } \\
\hline Cacao en polvo azucarado (2,5\% grasa) & $10 \mathrm{~g}$ \\
\hline Leche de vaca desnatada & $250 \mathrm{~g}$ \\
\hline Agua & $400 \mathrm{~g}$ \\
\hline Galletas & $40 \mathrm{~g}$ \\
\hline Cereales de desayuno & $30 \mathrm{~g}$ \\
\hline
\end{tabular}

\begin{tabular}{|l|c|}
\hline \multicolumn{2}{|c|}{ COMIDA } \\
\hline Sandia & $300 \mathrm{~g}$ \\
\hline Agua & $600 \mathrm{~g}$ \\
\hline Lechuga & $100 \mathrm{~g}$ \\
\hline Tomate & $30 \mathrm{~g}$ \\
\hline Cebolla & $20 \mathrm{~g}$ \\
\hline Pan blanco de trigo sin sal & $60 \mathrm{~g}$ \\
\hline Guisantes con calamares & 1 rac.-313g \\
\hline Boquerones fritos & 0.5 rac.-145.5g \\
\hline
\end{tabular}

\begin{tabular}{|l|c|}
\hline \multicolumn{2}{|c|}{ CENA } \\
\hline Agua & $200 \mathrm{~g}$ \\
\hline Gelatina & $30 \mathrm{~g}$ \\
\hline Pollo & $200 \mathrm{~g}$ \\
\hline Espaguetis & $100 \mathrm{~g}$ \\
\hline Plátano & $200 \mathrm{~g}$ \\
\hline Pan blanco de trigo sin sal & $60 \mathrm{~g}$ \\
\hline
\end{tabular}


Tabla 43. Resumen semanal dieta de descanso.

\begin{tabular}{|c|c|c|c|c|c|c|c|c|c|c|c|}
\hline & $\begin{array}{l}\text { Día } 1 \\
\text { Lunes }\end{array}$ & $\begin{array}{c}\text { Día } 2 \\
\text { Martes }\end{array}$ & $\begin{array}{c}\text { Día } 3 \\
\text { Miércoles }\end{array}$ & $\begin{array}{c}\text { Día } 4 \\
\text { Jueves }\end{array}$ & $\begin{array}{c}\text { Día } 5 \\
\text { Viernes }\end{array}$ & $\begin{array}{c}\text { Día } 6 \\
\text { Sábado }\end{array}$ & $\begin{array}{c}\text { Día } 7 \\
\text { Domingo }\end{array}$ & Total & Kcal & Media & $\% \mathrm{Kcal}$ \\
\hline \multicolumn{12}{|l|}{ GENERAL } \\
\hline Agua (g) & $2.734,35$ & $2.949,03$ & $2.926,81$ & $2.849,89$ & $3.039,41$ & $3.168,28$ & $3.248,36$ & $20.916,13$ & & $2.988,02$ & \\
\hline Energía (kcal) & $2.759,69$ & $2.864,74$ & $2.818,40$ & $2.724,99$ & $2.803,80$ & $2.840,39$ & $2.858,81$ & $19.670,82$ & $19.670,82$ & $2.810,12$ & $100 \%$ \\
\hline Energía (kJ) & $11.542,60$ & $11.980,08$ & $11.786,85$ & $11.400,17$ & $11.725,93$ & $11.883,94$ & $11.959,88$ & $82.279,45$ & & $11.754,21$ & \\
\hline Proteínas (g) & 123,16 & 152,87 & 131,48 & 133,58 & 126,77 & 113,71 & 167,71 & 949,28 & $3.797,12$ & 135,61 & $19,33 \%$ \\
\hline Grasa total (g) & 92,02 & 109,17 & 81,72 & 98,11 & 85,63 & 74,49 & 70,98 & 612,12 & $5.509,08$ & 87,45 & $28,05 \%$ \\
\hline Hidratos de carbono totales (g) & 359,56 & 317,56 & 388,59 & 327,01 & 378 & 428,22 & 385,15 & $2.584,09$ & $10.336,36$ & 369,16 & $52,62 \%$ \\
\hline Azúcares (g) & 77,66 & 94,42 & 165,39 & 106,9 & 100,37 & 127,93 & 144 & 816,67 & & 116,67 & \\
\hline Almidón (g) & 282,15 & 223,25 & 223,36 & 220,21 & 277,89 & 300,37 & 241,23 & $1.768,46$ & & 252,64 & \\
\hline Fibra dietética (g) & 23,37 & 22,52 & 26,86 & 26,14 & 24,96 & 23,03 & 35,81 & 182,69 & & 26,10 & \\
\hline Grasa saturada (AGS) (g) & 26,28 & 35,12 & 29,25 & 27,69 & 24,66 & 21,12 & 20,93 & 185,05 & $1.665,45$ & 26,44 & $9,39 \%$ \\
\hline Grasa monoinsaturada (AGM) (g) & 39,62 & 41,84 & 31,61 & 42,14 & 32,05 & 31,59 & 30,02 & 248,87 & $2.239,83$ & 35,55 & $12,62 \%$ \\
\hline Grasa poliinsaturada (AGP) (g) & 16,04 & 19,69 & 14,67 & 20,07 & 19,83 & 14,81 & 13,95 & 119,06 & $1.071,54$ & 17,01 & $6,04 \%$ \\
\hline Colesterol (mg) & 293,5 & 526,44 & 490,74 & 596,36 & 168,88 & 605,58 & 492,24 & $3.173,74$ & & 453,39 & \\
\hline \multicolumn{12}{|l|}{ MINERALES } \\
\hline Calcio (mg) & 785,99 & $1.352,78$ & $1.541,55$ & $1.057,52$ & $1.082,16$ & $1.748,22$ & $1.455,29$ & $9.023,51$ & & $1.289,07$ & \\
\hline Hierro (mg) & 20,78 & 15,72 & 20,95 & 27,77 & 20,34 & 21,45 & 21,34 & 148,35 & & 21,19 & \\
\hline Yodo (ug) & 249,53 & 641,07 & 727,26 & 534,21 & 507,07 & 622,06 & 544,33 & $3.825,53$ & & 546,50 & \\
\hline Magnesio (mg) & 329,41 & 387,39 & 472,05 & 382,14 & 399,9 & 357,14 & 431,15 & $2.759,18$ & & 394,17 & \\
\hline Cinc (mg) & 13,7 & 11,33 & 10,76 & 10,8 & 12,76 & 14,94 & 12,85 & 87,14 & & 12,45 & \\
\hline Sodio (mg) & $3.407,24$ & $5.369,14$ & $5.176,43$ & $10.161,93$ & $2.765,62$ & $2.350,72$ & $2.805,38$ & $32.036,46$ & & $4.576,64$ & \\
\hline Potasio (mg) & $4.385,19$ & $4.711,57$ & $5.969,83$ & $4.723,32$ & $5.745,99$ & $4.453,25$ & $4.704,62$ & $34.693,77$ & & $4.956,25$ & \\
\hline Fósforo (mg) & $1.611,12$ & $2.336,91$ & $2.496,48$ & $2.147,50$ & $2.149,58$ & $2.340,92$ & $2.534,16$ & $15.616,67$ & & $2.230,95$ & \\
\hline Selenio ( $\mu \mathrm{g})$ & 0,00 & 0,00 & 0,00 & 0,00 & 123,33 & 0,00 & 0,00 & 123,33 & & 17,62 & \\
\hline \multicolumn{12}{|l|}{ VITAMINAS } \\
\hline Tiamina o Vitamina B1 (mg) & 4,41 & 1,54 & 2,06 & 2,1 & 1,84 & 1,77 & 2,12 & 15,84 & & 2,26 & \\
\hline Riboflavina o Vitamina B2 (mg) & 2,77 & 1,88 & 3,11 & 2,86 & 2,21 & 2,52 & 2,67 & 18,02 & & 2,57 & \\
\hline Eq. niacina (mg) & 56,18 & 39,42 & 50,58 & 49,77 & 61,18 & 37,12 & 56,41 & 350,66 & & 50,09 & \\
\hline Vitamina B6 (mg) & 3,21 & 2,38 & 3,52 & 2,82 & 2,76 & 2,43 & 3,62 & 20,74 & & 2,96 & \\
\hline Ácido fólico $(\mu \mathrm{g})$ & 330,24 & 265,76 & 438,75 & 342,75 & 297,66 & 348,09 & 390,36 & $2.413,61$ & & 344,80 & \\
\hline Vitamina B12 (ug) & 6,11 & 11,84 & 12,46 & 5,17 & 10,23 & 8,68 & 5,16 & 59,65 & & 8,52 & \\
\hline Vitamina C (mg) & 107,04 & 121,23 & 164,22 & 95,94 & 145,5 & 91,17 & 84,46 & 809,56 & & 115,65 & \\
\hline Vitamina A: Eq. retinol ( $\mu \mathrm{g})$ & 293,19 & 775,11 & 591,35 & 768,52 & 556,27 & $1.356,54$ & 505,59 & $4.846,57$ & & 692,37 & \\
\hline Retinol $(\mu \mathrm{g})$ & 187 & 449,21 & 418,86 & 338,84 & 270,24 & 249,53 & 201,13 & $2.114,81$ & & 302,12 & \\
\hline Carotenos ( $\mu \mathrm{g})$ & 658,21 & $1.280,38$ & $1.106,55$ & $2.972,00$ & $1.752,62$ & $5.837,20$ & $1.151,01$ & $14.757,97$ & & $2.108,28$ & \\
\hline Vitamina D ( $\mu \mathrm{g})$ & 3,8 & 1,38 & 2,61 & 3,4 & 37,6 & 3,01 & 8,4 & 60,20 & & 8,60 & \\
\hline Vitamina E (mg) & 3 & 5,54 & 5,5 & 4,97 & 5,59 & 9,99 & 6,18 & 40,77 & & 5,82 & \\
\hline \multicolumn{12}{|l|}{ ÁCIDOS GRASOS } \\
\hline Grasa total (g) & 92,02 & 109,17 & 81,72 & 98,11 & 85,63 & 74,49 & 70,98 & 612,12 & & 87,45 & \\
\hline Grasa saturada (AGS) (g) & 26,28 & 35,12 & 29,25 & 27,69 & 24,66 & 21,12 & 20,93 & 185,05 & & 26,44 & \\
\hline Grasa monoinsaturada (AGM) (g) & 39,62 & 41,84 & 31,61 & 42,14 & 32,05 & 31,59 & 30,02 & 248,87 & & 35,55 & \\
\hline Grasa poliinsaturada (AGP) (g) & 16,04 & 19,69 & 14,67 & 20,07 & 19,83 & 14,81 & 13,95 & 119,06 & & 17,01 & \\
\hline Colesterol (mg) & 293,5 & 526,44 & 490,74 & 596,36 & 168,88 & 605,58 & 492,24 & $3.173,74$ & & 453,39 & \\
\hline C12:0 (g) - Ac. láurico - Ac. dodecanoico & 0,29 & 1,12 & 5,26 & 0,53 & 0,53 & 0,6 & 0,52 & 8,85 & & 1,26 & \\
\hline C14:0 (g) - Ac. mirístico - Ac. tetradecanoico & 0,91 & 3,09 & 2,97 & 0,82 & 0,94 & 0,69 & 0,81 & 10,23 & & 1,46 & \\
\hline C16:0 (g) - Ac. palmítico - Ac. hexadecanoico & 14,89 & 13,14 & 11,91 & 16,82 & 13,99 & 9,39 & 9,85 & 89,99 & & 12,86 & \\
\hline C18:0 (g) - Ac. esteárico - Ac. octadecanoico & 6,98 & 5,12 & 5,52 & 7,44 & 6,69 & 3,81 & 3,64 & 39,20 & & 5,60 & \\
\hline C18:1 (g) - Ac. oleico - Ac. octadecenoico & 37,22 & 30,96 & 29,61 & 39,45 & 29,19 & 29,42 & 27,46 & 223,31 & & 31,90 & \\
\hline C18:2 (g) - Ac. linoleico - Ac. octadecadienoico & 13,94 & 13,01 & 12,54 & 17,38 & 12,92 & 12,68 & 10,15 & 92,62 & & 13,23 & \\
\hline C18:3 (g) - Ac. a-linolénico - Ac. octadecatrienoico & 0,93 & 1,03 & 0,87 & 1,23 & 1 & 0,66 & 1 & 6,72 & & 0,96 & \\
\hline C20:4 (g) - Ac. araquidónico - Ac. eicosatetraenoico & 0,29 & 0,05 & 0,02 & 0,12 & 0,25 & 0,07 & 0,06 & 0,86 & & 0,12 & \\
\hline C20:5 (g) - EPA - Ac. eicosapentaenoico & 0 & 0,11 & 0,12 & 0 & 1,04 & 0,31 & 0,75 & 2,33 & & 0,33 & \\
\hline C22:6 (g) - DHA - Ac. docosahexaenoico & 0 & 0,2 & 0,09 & 0 & 3,31 & 0,19 & 1,37 & 5,16 & & 0,74 & \\
\hline Ácidos grasos cis (g) & 48,68 & 25,91 & 38,98 & 55,41 & 39,64 & 26,29 & 33,77 & 268,68 & & 38,38 & \\
\hline
\end{tabular}




\section{CONCLUSIONES}

Como se ha podido ver a lo largo de este trabajo, la ciencia ha tratado de describir los requerimientos energéticos, fisiológicos y nutricionales del baloncesto. A pesar de las diferencias que se han encontrado en las distintas publicaciones, existe un gran marco común sobre el que es posible trabajar y que sirve como base para plantear propuestas nutricionales a jugadores de baloncesto a nivel amateur sin necesidad de grandes costos. No hay que olvidar nunca que la figura encargada de controlar la alimentación debe ser la del nutricionista, ya que es el profesional mejor preparado parar ello. A pesar de esto, la realidad en el deporte amateur es otra muy diferente y, a día de hoy, esta figura es prácticamente inexistente fuera del deporte profesional. Por ello, con este trabajo se ha querido ilustrar de forma real los pasos a seguir para tratar de mejorar la nutrición de nuestro joven deportista. Es evidente la dificultad y tiempo que tiene la planificación en este ámbito para los entrenadores y propios jugadores, pero es un aspecto muy importante en la salud y rendimiento de los deportistas y por tanto no debería obviarse.

Las características del baloncesto, en el que no hay un periodo único y limitado de competición, sino que se desarrolla a lo largo de toda una temporada, hace que resulte de vital importancia la adquisición de unos hábitos alimenticios saludables. Para ello es más importante que el deportista tome conciencia de sus hábitos y se le den una serie de recomendaciones que lleve a cabo a lo largo de los meses, antes que una intervención puntual enfocada en un breve periodo de tiempo.

\section{REFERENCIAS}

Alarcón, F., Ureñá, N., García, J. J., y García, J. V. (2008). Análisis de la ingesta de alimentos en competición en equipos de baloncesto. IV Congreso Internacional y XXV Nacional de educación física. Universidad de Córdoba, Córdoba, España. Recuperado de: http://www.uco.es/IVCongresolnternacionalEducacionFisica/congreso/Documen tos/001-217-555-004-001.html

Blas, C., y Vázquez, Y. (2000). Guía práctica para interpretar un análisis de sangre. Sportlife, 10, 46-47.

Cometti, G. (2002). La preparación física en el baloncesto. Barcelona: Paidotribo.

Earle, R. W., y Baechle, T. R. (2004). Manual NSCA: Fundamentos del entrenamiento personal. Barcelona: Paidotribo.

Eugene, A. C., y Agwubuike, E. O. (2012). The Interface of Nutritional Practices of Selected Basketball Players of Nnamdi Azikiwe University, Awka, On Performance. Global journal of health science, 4(5), 192.

Federación Internacional Baloncesto (2014). Reglas oficiales de Baloncesto 2014. Recuperado: $\quad 4 / 04 / 2015$

de http://cmaab.es/pdf/Reglas de Juego FIBA 2014.pdf

Franco, L. B. (1998). Fisiología del baloncesto. Arch. Med. Deporte, 15 (68), 479-483.

González-Cross, M. M. (1994). Valoración crítica del estado nutritivo de jugadores de fútbol y baloncesto de las divisiones inferiores. Problemática nutricional de los 
deportes de equipo. (Tesis doctoral). Universidad Complutense de Madrid, Madrid.

Lorenzo, A. (2001). Entrenamiento de la resistencia aplicada al baloncesto. En Preparación física en baloncesto de formación y alto nivel. Curso de Especialización a la preparación física. Madrid: Gymnos.

Martínez-Sanz, J. M., Otegui, A. U., Guerrero, J., y Barrios, V. (2011). El somatotipomorfología en los deportistas. ¿Cómo se calcula? ¿Cuáles son las referencias internacionales para comparar con nuestros deportistas? Lecturas: Educación Física y Deportes, Revista Digital, 159. Recuperado de http://www.efdeportes.com/efd159/el-somatotipo-morfologia-en-losdeportistas.htm

Martínez-Sanz, J. M., Urdampilleta, A., y Mielgo-Ayuso, J. (2013). Necesidades energéticas, hídricas y nutricionales en el deporte. Motricidad. European Journal of Human Movement, 30, 37-52. Recuperado de:

http://redalyc.org/articulo.oa?id=274228060004

Mishchenko V. S., y Monogarov V. D. (2001). Fisiología del deportista ( $2^{\underline{a}}$ ed.). Barcelona: Paidotribo.

Palacios, N., Montalvo, Z., y Ribas, A. M. (2009). Alimentación, Nutrición e Hidratación en el Deporte. Madrid: Consejo Superior de Deporte.

Rodríguez, M., y García, I. (2008). Nutrición y dieta en el deporte. Aspectos básicos a tener presentes en jugadores profesionales de baloncesto. EF Deportes Revista Digital 12 (118). Recuperado de: http://www.efdeportes.com/efd118/ nutricion-y-dieta-en-el-deporte.htm

Ruiz, J., Mesa, J. L., Mula, F. J., Gutiérrez, Á., y Castillo, M. J. (2002). Hidratación y rendimiento: pautas para una elusión efectiva de la deshidratación por ejercicio. Apunts. Educación Física y Deportes, 70, 26-33.

Williams, M. (2002). Nutrición para la salud la condición física y el deporte. Barcelona: Paidotribo.

Wilmore, J. H., y Costill, D. L. (2004). Fisiología del esfuerzo y del deporte. Badalona: Paidotribo.

Zaragoza, J. (1996). Baloncesto: Conclusiones para el entrenamiento a partir del análisis de la actividad competitiva. Red: Revista de Entrenamiento Deportivo, 10(2), 21-27. 